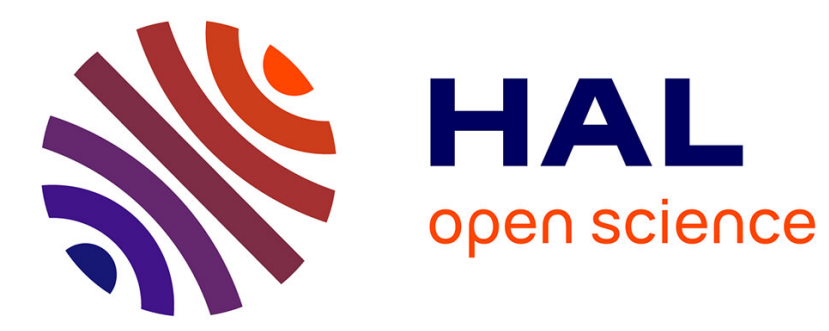

\title{
Antagonistic mixing in micelles of amphiphilic polyoxometalates and hexaethylene glycol monododecyl ether
}

\author{
Andi Di, Julien Schmitt, Kun Ma, Marcelo da Silva, Naomi Elstone, Najet \\ Mahmoudi, Peixun Li, Adam Washington, Zi Wang, R. John Errington, et al.
}

\section{To cite this version:}

Andi Di, Julien Schmitt, Kun Ma, Marcelo da Silva, Naomi Elstone, et al.. Antagonistic mixing in micelles of amphiphilic polyoxometalates and hexaethylene glycol monododecyl ether. Journal of Colloid and Interface Science, 2020, 578, pp.608-618. 10.1016/j.jcis.2020.06.007 . hal-03037745

\section{HAL Id: hal-03037745 \\ https://hal.science/hal-03037745}

Submitted on 3 Dec 2020

HAL is a multi-disciplinary open access archive for the deposit and dissemination of scientific research documents, whether they are published or not. The documents may come from teaching and research institutions in France or abroad, or from public or private research centers.
L'archive ouverte pluridisciplinaire HAL, est destinée au dépôt et à la diffusion de documents scientifiques de niveau recherche, publiés ou non, émanant des établissements d'enseignement et de recherche français ou étrangers, des laboratoires publics ou privés. 


\section{Journal Pre-proofs}

Antagonistic Mixing in Micelles of Amphiphilic Polyoxometalates and Hexaethylene Glycol Monododecyl Ether

Andi Di, Julien Schmitt, Kun Ma, Marcelo A. Da Silva, Naomi S. Elstone, Najet Mahmoudi, Peixun Li, Adam Washington, Zi Wang, R. John Errington, Karen J. Edler

PII: S0021-9797(20)30759-1

DOI: https://doi.org/10.1016/j.jcis.2020.06.007

Reference: YJCIS 26504

To appear in: $\quad$ Journal of Colloid and Interface Science

Received Date: $\quad 9$ April 2020

Revised Date: $\quad 31$ May 2020

Accepted Date: $\quad 2$ June 2020

Please cite this article as: A. Di, J. Schmitt, K. Ma, M.A. Da Silva, N.S. Elstone, N. Mahmoudi, P. Li, A. Washington, Z. Wang, R.J. Errington, K.J. Edler, Antagonistic Mixing in Micelles of Amphiphilic Polyoxometalates and Hexaethylene Glycol Monododecyl Ether, Journal of Colloid and Interface Science (2020), doi: https://doi.org/10.1016/j.jcis.2020.06.007

This is a PDF file of an article that has undergone enhancements after acceptance, such as the addition of a cover page and metadata, and formatting for readability, but it is not yet the definitive version of record. This version will undergo additional copyediting, typesetting and review before it is published in its final form, but we are providing this version to give early visibility of the article. Please note that, during the production process, errors may be discovered which could affect the content, and all legal disclaimers that apply to the journal pertain.

(C) 2020 Published by Elsevier Inc. 
Antagonistic Mixing in Micelles of Amphiphilic Polyoxometalates and Hexaethylene Glycol Monododecyl Ether

Andi Di, ${ }^{1}$ Julien Schmitt, ${ }^{1,2}$ Kun Ma ${ }^{3}$ Marcelo A. Da Silva, ${ }^{1}$ Naomi S. Elstone,${ }^{1}$ Najet Mahmoudi, ${ }^{3}$ Peixun Li, ${ }^{3}$ Adam Washington, ${ }^{3}$ Zi Wang, ${ }^{3}$ R. John Errington, ${ }^{5}$ Karen J. Edler $^{1^{*}}$

${ }^{1}$ Department of Chemistry, University of Bath, Bath, BA2 7AY, UK

${ }^{2}$ LSFC - Laboratoire de Synthèse et Fonctionnalisation des Céramiques, UMR 3080 CNRS / SaintGobain CREE, Saint-Gobain Research Provence, 550 avenue Alphose Jauffret, Cavaillon, France ${ }^{3}$ ISIS Neutron and Muon Source, Science and Technology Facilities Council, Rutherford Appleton Laboratory, Didcot OX11 0QX, UK

${ }^{4}$ Chemistry, School of Natural and Environmental Sciences, Newcastle University, Newcastle upon Tyne, NE1 7RU, UK

*Corresponding author:

Email: K.Edler@bath.ac.uk

\section{Graphical Abstract}

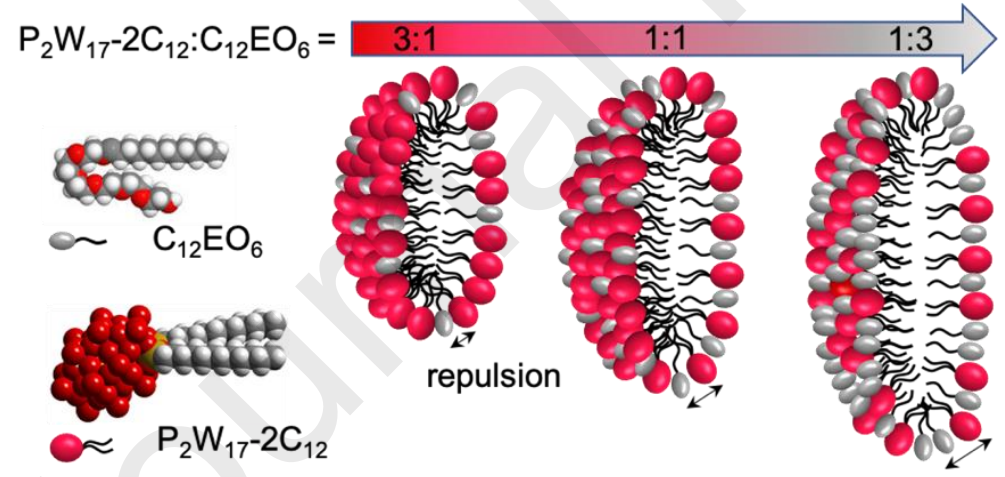

\section{Abstract}

\section{Hypothesis}

Polyoxometalates (POMs) are metal oxygen clusters with a range of interesting magnetic and catalytic properties. POMs with attached hydrocarbon chains show amphiphilic behaviour so we hypothesised that mixtures of a non-ionic surfactant and anionic surfactants with a polyoxometalate cluster as headgroup would form 
mixed micelles, giving control of the POM density in the micelle, but which would differ in size and shape from micelles formed by the individual surfactants. Due to the high charge and large size of the POM, we suggested that these would be nonideal mixtures due to the complex interactions between the two types of surfactants. The nonideality and the micellar composition may be quantified using regular solution theory. With supplementary information provided by small-angle neutron scattering, an understanding of this unusual binary surfactant system can be established.

\section{Experiments}

A systematic study was performed on mixed surfactant systems containing polyoxometalate-headed amphiphiles $\left(\mathrm{K}_{10}\left[\mathrm{P}_{2} \mathrm{~W}_{17} \mathrm{O}_{61} \mathrm{OSi}_{2}\left(\mathrm{C}_{\mathrm{n}} \mathrm{H}_{2 \mathrm{n}+1}\right)_{2}\right]\right.$, abbreviated as $\mathrm{P}_{2} \mathrm{~W}_{17}-2 \mathrm{C}_{n}$, where $\mathrm{n}=12,14$ or 16 ) and hexaethylene glycol monododecyl ether $\left(\mathrm{C}_{12} \mathrm{EO}_{6}\right)$. Critical micelle concentrations (CMCs) of these mixtures were measured and used to calculate the interaction parameters based on regular solution theory, enabling prediction of micellar composition. Predictions were compared to micelle structures obtained from small angle neutron scattering (SANS). A phase diagram was also established.

\section{Findings}

The CMCs of these mixtures suggest unusual unfavourable interactions between the two species, despite formation of mixed micelles. Micellar compositions obtained from SANS concurred with those calculated using the averaged interaction parameters for $\mathrm{P}_{2} \mathrm{~W}_{17}-2 \mathrm{C}_{n} / \mathrm{C}_{12} \mathrm{EO}_{6}(\mathrm{n}=12$ and 14$)$. We attribute the unfavourable interactions to a combination of different phenomena: counterion-mediated interactions between $\mathrm{P}_{2} \mathrm{~W}_{17}$ units and the unfolding of the ethylene oxide headgroups 
of the nonionic surfactant, yet micelles still form in these systems due to the hydrophobic interactions between surfactant tails.

Keywords: polyoxometallate amphiphiles, hexaethylene glycol monododecyl ether, unfavourable mixing, micellar composition, small angle neutron scattering

Self-organised nanostructures, achieved by the self-assembly of amphiphilic molecules, such as micelles, vesicles and emulsions, have been widely studied and have many applications in the fields of supramolecular chemistry ${ }^{1}$ and catalysis. ${ }^{2,3}$ Those nanostructures also provide an efficient way to build mesoscopic structures from discrete particles. Polyoxometalates (POMs), inorganic metal-oxygen cluster anions, are fascinating nanomaterials due to their diverse magnetic, catalytic, chemical, and electronic properties. ${ }^{4-7}$ Their redox properties have been thoroughly investigated ${ }^{8}$ but the creation of structures in which the POM units are well-organised within the nanostructures remains a challenge.

Hybrid POM-organic amphiphiles are promising candidates to achieve such organisation of POM units in the system. They also provide new supramolecular structures to further exploit their remarkable properties and support the manufacturing of nanofunctional materials for extensive applications in electronic device fabrication and in catalysis. ${ }^{9-11}$ Therefore, the development of suitable methods to modify POM frameworks with organic groups through electrostatic interactions and covalent linkages have been a focus of interest in this field. Due to the strong stabilities of covalent linkages compared to electrostatic interactions, studies have endeavoured to functionalise the POM cage through building covalent bonds to organic groups, ${ }^{12-14}$ to achieve well-organised nanostructures. Interesting 
self-assembled amphiphilic structures have been detected, such as vesicles, ${ }^{15-17}$ cylindrical micelles ${ }^{16}$ or emulsions. ${ }^{18}$

In our previous work, we attached double hydrocarbon chains onto a Dawson-type polyoxometalate, $\left[\mathrm{P}_{2} \mathrm{~W}_{17} \mathrm{O}_{61}\right]^{10-}$ ions $\left(\mathrm{P}_{2} \mathrm{~W}_{17}\right)$, producing $\mathrm{P}_{2} \mathrm{~W}_{17}-2 \mathrm{C}_{\mathrm{n}}$ surfactants, with $\mathrm{P}_{2} \mathrm{~W}_{17}$ as the headgroup and $2 \mathrm{C}_{\mathrm{n}}$ standing for the double hydrocarbon chains of length $n=12,14,16$ or 18 . The micelles formed by these surfactants have shown redox properties in water and the potential to functionalise mesostructured materials. ${ }^{19}$ This previous study evidenced that these micelles bear a quite high surface charge arising from the multiply charged nature of the POM headgroups, which results in unusual self-assembly behaviour. This has motivated us to investigate the mixed systems of $\mathrm{P}_{2} \mathrm{~W}_{17}-2 \mathrm{C}_{\mathrm{n}}$ surfactants with commercial nonionic surfactants to understand the interactions between the highly charged POM-headed surfactant $\left(\mathrm{P}_{2} \mathrm{~W}_{17}-2 \mathrm{C}_{\mathrm{n}}\right)$ and other species. Due to the high negative charge of the $\mathrm{P}_{2} \mathrm{~W}_{17}-2 \mathrm{C}_{\mathrm{n}}$ headgroups, large repulsive interactions or co-precipitation are expected to occur if mixed with an anionic or a cationic surfactant. We have therefore chosen to investigate mixtures of a commonly used polyethylene oxide-headed nonionic surfactant, $\mathrm{C}_{12} \mathrm{EO}_{6}$, with the $\mathrm{P}_{2} \mathrm{~W}_{17}-2 \mathrm{C}_{\mathrm{n}}$ surfactants. The investigation of these mixed systems with controllable molecular composition and architectures will provide a fundamental understanding of unusual mixed systems. These mixtures may also find applications in the synthesis of functional mesostructured materials by tuning the surfactants ratio, and hence the $\mathrm{P}_{2} \mathrm{~W}_{17}$ concentration in the prepared materials.

In this paper, we present the measured CMC values of the mixed systems, alongside SANS measurements on mixed micelles of $\mathrm{P}_{2} \mathrm{~W}_{17}-2 \mathrm{C}_{\mathrm{n}}$ with $\mathrm{C}_{12} \mathrm{EO}_{6}$. For these experiments, the surfactant composition of the solutions was varied at a fixed overall surfactant concentration. By measuring the CMCs of the mixtures, we could derive 
the micellar interaction parameter using the regular solution theory ${ }^{20}$ and hence a theoretical micellar composition. By fitting the SANS data, we derived the geometries and the aggregation numbers $\left(N_{\text {agg }}\right)$ of the mixed micelles. The mole fractions of $\mathrm{C}_{12} \mathrm{EO}_{6}$ in the micelles were determined by isotopic substitution, compared with our predictions. We hence showed this system behaves as a nonideal mixing.

\section{Experimental Methods}

Materials. Fully hydrogenated hexaethylene glycol monododecyl ether $\left(h-\mathrm{C}_{12} \mathrm{EO}_{6}\right.$, purity $>98 \%)$ and deuterium oxide $\left(\mathrm{D}_{2} \mathrm{O}, 99.9\right.$ atom $\% \mathrm{D}$, conductivity $\left.\leq 150 \mu \mathrm{S} \mathrm{cm} \mathrm{cm}^{-1}\right)$ were purchased from Sigma Aldrich and were used as supplied. $P_{2} W_{17}-2 C_{n}(n=12$, 14, 16 and 18, the length of the double hydrocarbon tails) were synthesised according to an established protocol ${ }^{19}$ (synthesis details can be found in the supporting information and the structure of the surfactant is illustrated in SI Figure 1). All the $P_{2} W_{17}-2 C_{n}$ materials used in this paper had hydrogenated tails. Taildeuterated $\mathrm{C}_{12} \mathrm{EO}_{6}$ (98 atom $\mathrm{D} \%$, purity > 98\%) was provided by the STFC Deuteration Facility at ISIS Neutron and Muon Facility at Didcot and is referred to by the abbreviation $\mathrm{d}-\mathrm{C}_{12} \mathrm{EO}_{6}$.

$\mathrm{P}_{2} \mathrm{~W}_{17}-2 \mathrm{C}_{\mathrm{n}}(\mathrm{n}=12,14,16$ and 18$)$ were used as-synthesised without further purification for SANS measurements. All hydrogenated surfactant solutions were prepared in $\mathrm{D}_{2} \mathrm{O}$ and 70 mol\% $\mathrm{D}_{2} \mathrm{O} .70 \mathrm{~mol} \% \mathrm{D}_{2} \mathrm{O}$ was diluted from pure $\mathrm{D}_{2} \mathrm{O}$ using ultrapure water $(18.2 \mathrm{M} \Omega \cdot \mathrm{cm}$, from an ELGA PURELAB flex water purification system). $\mathrm{P}_{2} \mathrm{~W}_{17-2}-\mathrm{C}_{\mathrm{n}} / \mathrm{d}-\mathrm{C}_{12} \mathrm{EO}_{6}$ mixtures were prepared in $\mathrm{D}_{2} \mathrm{O}$.

Critical Micelle Concentration (CMC) measurements. We have previously reported the CMCs of the pure $\mathrm{P}_{2} \mathrm{~W}_{17}-2 \mathrm{C}_{n}$ surfactants $(\mathrm{n}=12,14,16$ and 18$) .{ }^{19}$ The 
$\mathrm{CMC}$ of the $\mathrm{C}_{12} \mathrm{EO}_{6}$ in water was measured using a Du Noüy Ring (Attension Sigma 701 Tensiometer). The CMCs of the binary systems were measured by either conductivity using a METTLER TOLEDO conductivity meter or by a pendant-drop method using a Kruss DSA100 at Diamond Light Source. For $\mathrm{P}_{2} \mathrm{~W}_{17}-2 \mathrm{C}_{n}$-rich mixtures, electrical conductivity measurements give $\mathrm{CMC}$ values with more accuracy, whereas surface tension measurements provide more accurate results for the $\mathrm{C}_{12} \mathrm{EO}_{6}$-rich mixtures. Both conductivity and surface tension measurements were reproduced four times, and the results are the averages of the four measurements. It is worth noting that the $C M C s$ for the $\mathrm{P}_{2} \mathrm{~W}_{17}-2 \mathrm{C}_{18} / \mathrm{C}_{12} \mathrm{EO}_{6}$ mixtures were too low to be measured accurately using the two techniques mentioned above, so are not included in this manuscript.

SANS Data collection. SANS experiments were performed on the $\mathrm{LOQ}^{21}$ and LARMOR $^{22}$ instruments in Target Station I and II, respectively at the ISIS Neutron and Muon Spallation Source, Oxfordshire, UK.

The samples were measured in $1 \mathrm{~cm}$ wide, $1 \mathrm{~mm}$ path-length optical quartz cells at $25^{\circ} \mathrm{C}$, using a thermostat-controlled circulating bath. Samples were measured for 40 $\mu \mathrm{A}\left(\mathrm{D}_{2} \mathrm{O}\right)$ and $80 \mu \mathrm{A}\left(70 \mathrm{~mol} \% \mathrm{D}_{2} \mathrm{O}\right)$ of neutron current on the LOQ instrument. For experiments on LARMOR, mixtures containing $\mathrm{P}_{2} \mathrm{~W}_{17}-2 \mathrm{C}_{n}$ with $\mathrm{d}-\mathrm{C}_{12} \mathrm{EO}_{6}$ in $\mathrm{D}_{2} \mathrm{O}$ were measured for $20 \mu \mathrm{A}$.

The raw data were corrected for sample transmission and backgrounds from the solvent, the sample cell and other instrumental background using standard workflows in the Mantid software package. ${ }^{23}$ Scattering data were normalised against the scattering from a partially-deuterated polystyrene blend of known molecular weight, converting it to the differential scattering cross section $d \Sigma / d \Omega(q$ ) (in 
an absolute scale of $\left.\mathrm{cm}^{-1}\right) \cdot{ }^{24}$ The output data are hence given in absolute scattered intensity, $I(q)$ in $\mathrm{cm}^{-1}$, versus the momentum transfer, $q$ in $\AA^{-1}$.

SANS data from all samples measured were labelled using the molar ratio between the two surfactants $X \equiv\left[P_{2} W_{17}-2 C_{n}\right] /\left[C_{12} E_{6}\right]=3: 1,1: 1$ and 1:3, with the overall surfactant concentrations $\left[\mathrm{P}_{2} \mathrm{~W}_{17}-2 \mathrm{C}_{n}\right]+\left[\mathrm{C}_{12} \mathrm{EO}_{6}\right]$ of 8 and $16 \mathrm{mM}$ in aqueous solutions. The corresponding mole fractions of $\mathrm{P}_{2} \mathrm{~W}_{17}-2 \mathrm{C}_{n}$ are $0.75,0.5$ and 0.25 , respectively. For $\mathrm{P}_{2} \mathrm{~W}_{17}-2 \mathrm{C}_{n} / \mathrm{C}_{12} \mathrm{EO}_{6}(\mathrm{n}=12$ and 14) systems, measurements were made with both surfactants fully hydrogenated and tail-deuterated $\mathrm{C}_{12} \mathrm{EO}_{6}$ mixed with hydrogenated $\mathrm{P}_{2} \mathrm{~W}_{17-2}-\mathrm{C}_{\mathrm{n}}$.

SANS Data analysis. SANS patterns were modelled using shape-dependent approaches, either a core-shell sphere model ${ }^{25}$ or core-shell ellipsoid model, ${ }^{26,}{ }^{27}$ using the Sasview software (version 4.2.1). Polydispersity was not accounted for since good fits were obtained for monodisperse models. Both models used here assume that the thickness of the shell is constant at all points around the sphere or the ellipsoid. A structure factor, the Hayter-Penfold Rescaled Mean Spherical Approximation (RMSA), ${ }^{28}$ was used to account for the intermicellar interactions. RMSA is appropriate for dilute solutions of charged spherical and ellipsoidal micelles with a small aspect ratio ${ }^{29,30}$ and gives a good fit to the data obtained. In this study, no external salt is added into these studied systems, and the CMC values are very low compared to the concentrations measured making the concentration of ions in solution negligible therefore, the salt concentration is set to zero during the fitting.

SANS fitting was carried out through a simultaneous approach at two different solvent contrasts, $\mathrm{D}_{2} \mathrm{O}$ and $70 \mathrm{~mol} \% \mathrm{D}_{2} \mathrm{O}$. The neutron scattering length density (SLD) of the solvents was calculated to be $6.35 \times 10^{-6} \AA^{-2}$ for $D_{2} O$ and $4.27 \times 10^{-6} \AA^{-2}$ for 70 mol\% $\mathrm{D}_{2} \mathrm{O}$. Hence the solvent SLDs were always fixed in the fitting process. 
Similarly, during the fitting of systems with hydrogenated surfactant mixtures, the micelle core SLDs (refer to the values given in SI Table 1), temperature (298 K) and the dielectric constant of solvent $\left(78.0 \text { for } \mathrm{D}_{2} \mathrm{O} \text { and } 78.2 \text { for } 70 \mathrm{~mol} \% \mathrm{D}_{2} \mathrm{O}\right)^{31}$ were all held at the known values. The minimum radius of the core of the micelles $\left(R_{\min }\right)$, the shell thickness $(t)$, the micellar charge $\left(Z_{m}\right)$, the shell SLD, the ellipticity $(\varepsilon$, for ellipsoids) and the volume fraction of micelles $(\varphi)$ were the fitting parameters.

$P_{2} W_{17}-C_{n} / d-C_{12} E O_{6}$ systems were treated differently while fitting. The parameters which were known from the experimental details (SLD of solvent) and the ones obtained from the fits of hydrogenated counterparts $\left(R_{\min }, \varepsilon, t\right.$ and $\left.\varphi\right)$ obtained from the modelling results of the equivalent fully hydrogenated $\mathrm{P}_{2} \mathrm{~W}_{17}-2 \mathrm{C}_{n} / \mathrm{C}_{12} \mathrm{EO}_{6}$ system were fixed. The core SLDs values were extracted from the fitting.

Experimental data were in good accordance with either the core-shell spherical model or core-shell ellipsoidal model with a core composed of the hydrophobic tails of the surfactant and a shell due mostly to the hydrophilic headgroups. $R_{\min }$ was always left free to vary during the fitting procedure while the core SLD was fixed to the value expected for saturated hydrocarbon chains for the fully hydrogenated binary surfactant systems during the data analysis process. Consequently, the shell can be formed only by the solvated $\mathrm{P}_{2} \mathrm{~W}_{17}$ and ethylene oxide headgroups but also by any counterions associated with the micelles and possibly part of the hydrocarbon chains due to the roughness of the shell-core interface. Due to the complexity of potential components in the shells, we did not attempt to evaluate the hydration of the shell in the analysis.

\section{Results}

CMC Determination. The CMCs of the $\mathrm{P}_{2} \mathrm{~W}_{17}-2 \mathrm{C}_{n}$ surfactants have been reported previously by our group and are presented in SI Table $2 .{ }^{19}$ The $\mathrm{CMC}$ value of $\mathrm{C}_{12} \mathrm{EO}_{6}$ 
obtained from surface tension measurements (SI Figure 2) was found to be $0.085 \pm$ $0.05 \mathrm{mM}$, which is consistent with the value reported in the literature. ${ }^{32}$ The CMCs of the $\mathrm{P}_{2} \mathrm{~W}_{17}-2 \mathrm{C}_{n} / \mathrm{C}_{12} \mathrm{EO}_{6}$ systems with various compositions were measured and are plotted in Figure 1. The surface tension and conductivity data used to determine these values can be found in the supporting information (see SI Figures 3, 4 and 5). CMCs of $\mathrm{P}_{2} \mathrm{~W}_{17}-2 \mathrm{C}_{18} / \mathrm{C}_{12} \mathrm{EO}_{6}$ could not be accurately determined and are not reported since either the electrical conductivities of the surfactant solutions were too low or the change of the surface tension values with the addition of the surfactants was within the error of the measurement. The surface tension measurements for the three other $P_{2} W_{17-2} C_{n}(n=12,14$ and 16) suggest the presence of small amounts of impurities in these $\mathrm{P}_{2} \mathrm{~W}_{17}-2 \mathrm{C}_{\mathrm{n}}$ surfactants, causing a slight dip below the average final surface tension at the point of the $\mathrm{CMC}$ (for example, $\mathrm{P}_{2} \mathrm{~W}_{17}-2 \mathrm{C}_{12} / \mathrm{C}_{12} \mathrm{EO}_{6}$ with $\mathrm{X}$ $\equiv 1: 1$, see SI Figure $3 b)$. The impurities may come from the excess of unreacted long-chain trichlorosilane molecules which were not completely washed out during the post-synthesis purification steps.

Table 1. $P_{2} W_{17}-2 C_{n}$ degree of ionisation in $P_{2} W_{17}-2 C_{n}: C_{12} E O_{6}=3: 1$ mixtures and pure $P_{2} W_{17}-2 C_{n}$ systems $(n=12,14$ and 16$)$

\begin{tabular}{ccc}
\hline Tail Length & $3: 1 \mathrm{P}_{2} \mathrm{~W}_{17}-2 \mathrm{C}_{\mathrm{n}}: \mathrm{C}_{12} \mathrm{EO}_{6}$ & $\mathrm{P}_{2} \mathrm{~W}_{17}-2 \mathrm{C}_{\mathrm{n}}{ }^{19}$ \\
\hline $\mathrm{n}=12$ & $0.61 \pm 0.05$ & $0.53 \pm 0.04$ \\
$\mathrm{n}=14$ & $0.45 \pm 0.05$ & $0.44 \pm 0.03$ \\
$\mathrm{n}=16$ & $0.40 \pm 0.04$ & $0.29 \pm 0.03$ \\
\hline
\end{tabular}

The degree of ionisation of the $\mathrm{P}_{2} \mathrm{~W}_{17}-2 \mathrm{C}_{n}$ molecules in the $\mathrm{P}_{2} \mathrm{~W}_{17}-2 \mathrm{C}_{n}$-rich mixtures were calculated using conductivity data ${ }^{33}$ and are listed in Table 1. These are higher than those of pure $\mathrm{P}_{2} \mathrm{~W}_{17}-2 \mathrm{C}_{\mathrm{n}}$ systems. ${ }^{19}$ We hypothesise that for the mixed systems, the insertion of nonionic surfactant molecules between the $\mathrm{P}_{2} \mathrm{~W}_{17}-2 \mathrm{C}_{n}$ molecules in the micelles increases the distance between anionic $\mathrm{P}_{2} \mathrm{~W}_{17}$ headgroups, reducing the electrostatic repulsion between them. Consequently, more counterions are able 
to dissociate from the surfactant headgroups compared to the pure $\mathrm{P}_{2} \mathrm{~W}_{17-}-2 \mathrm{C}_{\mathrm{n}}$ systems. For the $1: 1$ and 1:3 systems however conductivity could not reliably be used to determine the critical micelle concentrations, so the degree of ionisation of the $\mathrm{P}_{2} \mathrm{~W}_{17}-2 \mathrm{C}_{\mathrm{n}}$ in these solutions could not be determined.

The experimental $\mathrm{CMC}$ values of the mixtures with three different compositions are summarised in SI Table 2 and Figure 1. The CMC values decrease as the solution composition becomes increasingly nonionic-rich. This is consistent with trends seen in anionic-nonionic commercial surfactant mixtures that have been reported by others. ${ }^{34}$ Mixtures containing longer-chain $\mathrm{P}_{2} \mathrm{~W}_{17}-2 \mathrm{C}_{\mathrm{n}}$ also have lower CMCs compared to their shorter-chains counterparts with the same mixing ratio. ${ }^{35}$
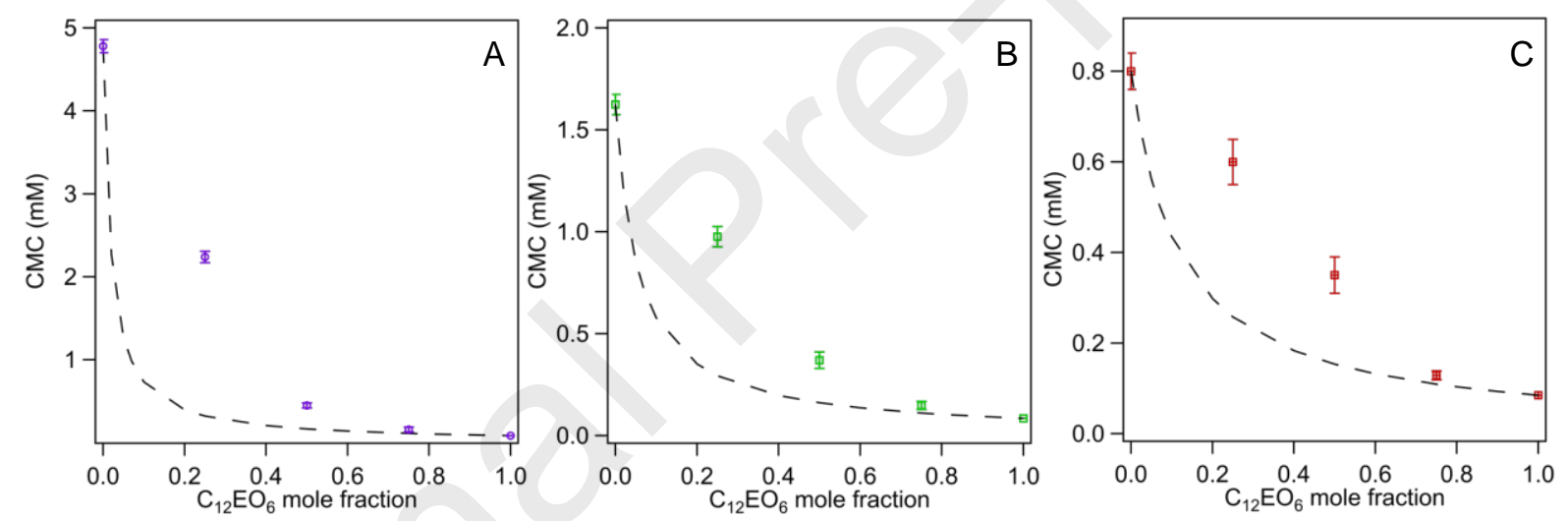

Figure 1. $C M C$ values for mixtures (A) $\mathrm{P}_{2} \mathrm{~W}_{17}-2 \mathrm{C}_{12} / \mathrm{C}_{12} \mathrm{EO}_{6}$ (B) $\mathrm{P}_{2} \mathrm{~W}_{17}-2 \mathrm{C}_{14} / \mathrm{C}_{12} \mathrm{EO}_{6}$ (C) $\mathrm{P}_{2} \mathrm{~W}_{17^{-}}$ $2 \mathrm{C}_{16} / \mathrm{C}_{12} \mathrm{EO}_{6}$ as a function of $\mathrm{C}_{12} \mathrm{EO}_{6}$ mole fraction in the mixture. The dashed line is the CMCs in the case of ideal mixing calculated using equation: $1 / C M C_{\text {ideal }}=x / C M C_{a}+(1-x) / C M C_{b}$, where $C M C_{a}$ and $C M C_{b}$ is the $C M C$ of $\mathrm{C}_{12} \mathrm{EO}_{6}$ and $\mathrm{P}_{2} \mathrm{~W}_{17}-2 \mathrm{C}_{n}$, respectively, $\mathrm{x}$ is the mole fraction of $\mathrm{C}_{12} \mathrm{EO}_{6}$. CMCs for $\mathrm{P}_{2} \mathrm{~W}_{17}-2 \mathrm{C}_{18} / \mathrm{C}_{12} \mathrm{EO}_{6}$ could not be measured accurately so it is not shown here.

The experimental CMCs of the mixtures, plotted as a function of $\mathrm{P}_{2} \mathrm{~W}_{17}-2 \mathrm{C}_{\mathrm{n}}$ mole fraction in Figure 1, are compared to the dependence of the CMCs predicted for ideal mixing (dashed line). Comparison of the experimental results and the CMCs estimated if the two surfactants are demixing into separate micelles are displayed in SI Figure 6. The experimental results follow neither the ideal mixing nor the demixing behaviour. The deviations from ideal mixing in mixed systems can be understood by 
using regular solution theory, ${ }^{20,36}$ expressed in terms of a single intermicellar interaction parameter, called $\beta$. The value of $\beta$ is related to the CMC of a mixed surfactant solution $\left(C M C_{\text {mix }}\right)$ via:

$$
\frac{1}{\mathrm{CMC}_{\text {mix }}}=\frac{\mathrm{x}_{1}}{\mathrm{f}_{1} \mathrm{CMC}_{1}}+\frac{1-\mathrm{x}_{1}}{\mathrm{f}_{2} \mathrm{CMC}_{2}}
$$

where $\mathrm{x}_{1}$ is the mole fraction of surfactant 1 , and $C M C_{1}$ and $C M C_{2}$ are the critical micelle concentrations of surfactant 1 and surfactant 2 separately. The activity coefficient $f_{1}$ and $f_{2}$ are expressed as a function of $\beta, f_{1}=\exp \left[\beta\left(1-x_{1}\right)^{2}\right]$ and $f_{2}=$ $\exp \left[\beta\left(x_{1}\right)^{2}\right]$. $\beta$ was calculated from the $C M C_{\text {mix }}$ for each mixture using Equation (1). The obtained $\beta$ value for each given composition and the averaged value $\bar{\beta}$ for each specified system are listed in combined with the isotopic substitution method to determine the micellar composition in order to compare with the values of Table 2.

Table 2. The calculated $\beta$ values, considering the errors, are roughly constant over the range of compositions studied for each mixed system, which is consistent with the report on mixtures within the regular solution approximation. ${ }^{37}$ Additionally, the mixed micelles were probed using SANS, combined with the isotopic substitution method to determine the micellar composition in order to compare with the values of Table 2.

Table 2. The calculated interaction parameters $\beta$ for the systems studied.

\begin{tabular}{ccccccc}
\hline $\mathrm{P}_{2} \mathrm{~W}_{17}-2 \mathrm{C}_{n}: \mathrm{C}_{12} \mathrm{EO}_{6}$ & $\beta(\mathrm{n}=12)$ & $\bar{\beta}(\mathrm{n}=12)$ & $\beta(\mathrm{n}=14)$ & $\bar{\beta}(\mathrm{n}=14)$ & $\beta(\mathrm{n}=16)$ & $\bar{\beta}(\mathrm{n}=16)$ \\
\hline $3: 1$ & $3.9 \pm 0.9$ & & $2.6 \pm 1.0$ & & $2.2 \pm 0.6$ & \\
$1: 1$ & $4.0 \pm 0.8$ & $4.4 \pm 0.8$ & $4.4 \pm 0.8$ & $3.7 \pm 0.8$ & $3.3 \pm 0.5$ & $3.0 \pm 0.6$ \\
$1: 3$ & $5.4 \pm 0.6$ & & $4.3 \pm 0.5$ & & $3.6 \pm 0.6$ & \\
\hline
\end{tabular}



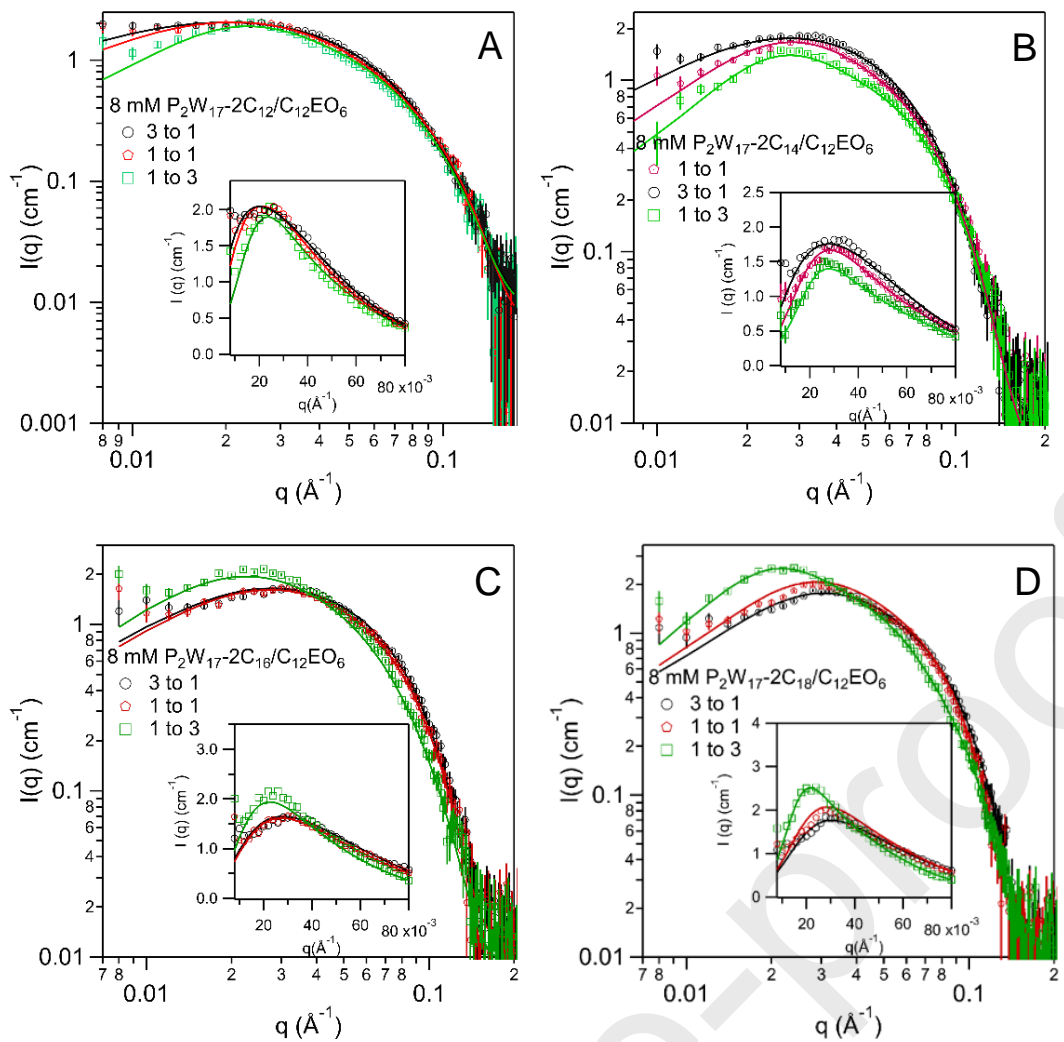

Figure 2. SANS data (I(q) versus $q)$ and fits for $h-P_{2} W_{17}-2 C_{n} / h-C_{12} E_{6}$ with $n=(A) 12$ (B) 14 (C) 16 and (D) 18 at a total concentration of $8 \mathrm{mM}$ in $\mathrm{D}_{2} \mathrm{O}$, given on a log-log scale. The insets correspond to the same scattering data plotted on a linear scale.

SANS structural characterisation. SANS data modelling gives information about the microstructure of these micellar systems. Figure 2 and Figure 3 show the SANS data and their fits for the hydrogenated- $\mathrm{P}_{2} \mathrm{~W}_{17}-2 \mathrm{C}_{\mathrm{n}} /$ hydrogenated- $\mathrm{C}_{12} \mathrm{EO}_{6}\left(\mathrm{~h}-\mathrm{P}_{2} \mathrm{~W}_{17^{-}}\right.$ $2 \mathrm{C}_{\mathrm{n}} / \mathrm{h}-\mathrm{C}_{12} \mathrm{EO}_{6}$ ) mixtures in $\mathrm{D}_{2} \mathrm{O}$ for the three mixing ratios and at a total surfactant concentration of $8 \mathrm{mM}$ and $16 \mathrm{mM}$ respectively. The same samples in $70 \mathrm{~mol} \% \mathrm{D}_{2} \mathrm{O}$ were also measured as another contrast to constrain the structure fitting (see SI Figure 7 and 8). The fits are in good agreement with the experimental data collected. Fitted parameters are given in Table 3. 

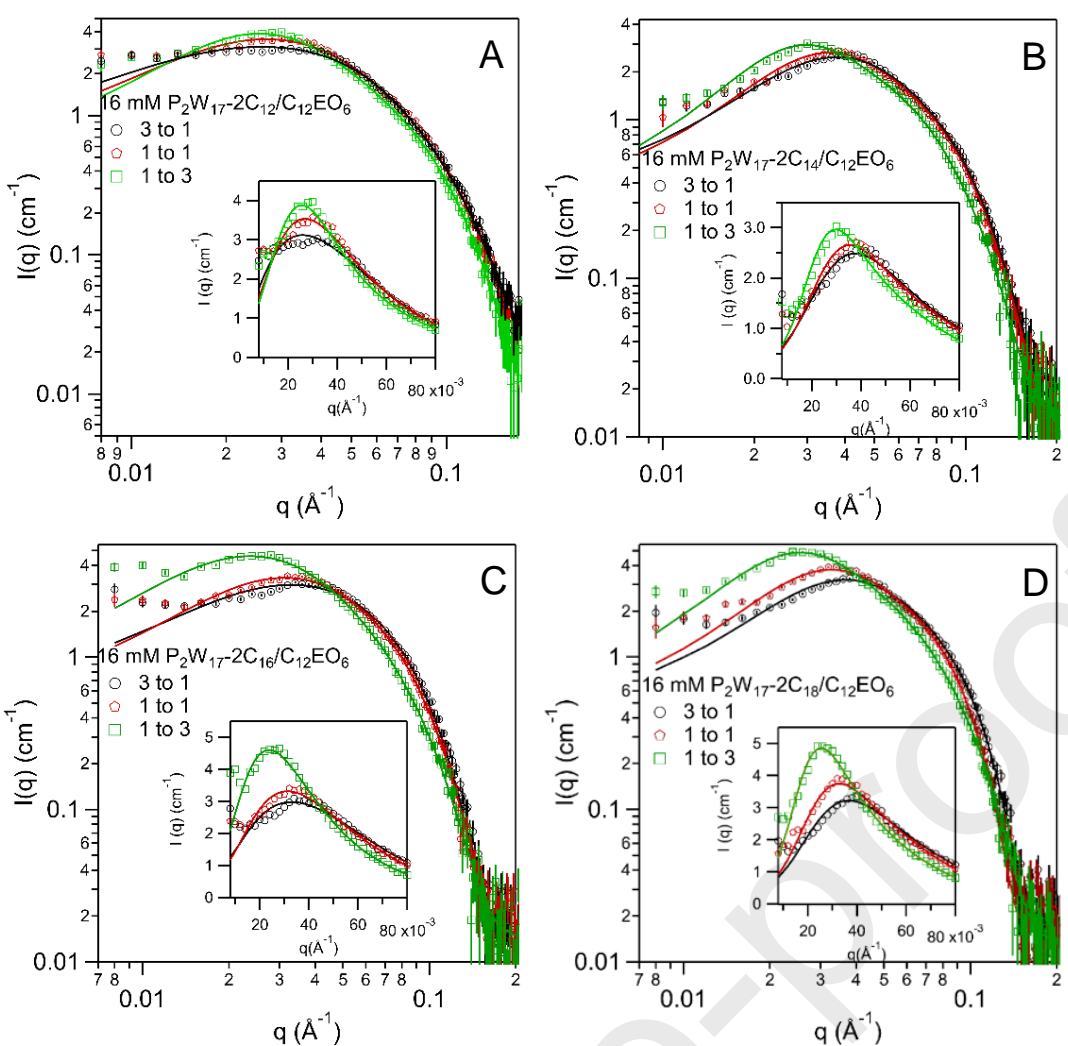

Figure 3. SANS data $(\mathrm{I}(\mathrm{q})$ versus $\mathrm{q})$ and fits for $\mathrm{P}_{2} \mathrm{~W}_{17-2}-\mathrm{C}_{n} / \mathrm{C}_{12} \mathrm{EO}_{6}$ with $\mathrm{n}=(\mathrm{A}) 12$ (B) 14 (C) 16 and (D) 18 at a total concentration of $16 \mathrm{mM}$ in $\mathrm{D}_{2} \mathrm{O}$, given on a log-log scale. The insets correspond scattering data plotted on a linear scale.

These graphs show plots of SANS data on both a linear (inset) and log-log scale. The use of a linear scale on $\mathrm{x}$-axis highlights the scattering caused by intermicellar interactions. After comparing the three patterns in each of the sub-graphs in Figure 2 (B) (C) (D) and Figure $3(A)(B)(C)(D)$, a peak arises in the linear scattering patterns at a position between $q=0.025$ and $0.035 \AA^{-1}$, due to the interactions between micelles. This peak shifts to lower $\mathrm{q}$ values and becomes sharper for solutions progressively richer in the nonionic surfactant. This indicates a greater micellar repulsion is present in solutions with a higher $\mathrm{C}_{12} \mathrm{EO}_{6}$ composition. This is further demonstrated by the micellar surface charge parameter $Z_{m}$ extracted from data fitting listed in Table 3. This effect becomes more prominent as the hydrophobic tails of $\mathrm{P}_{2} \mathrm{~W}_{17}-2 \mathrm{C}_{\mathrm{n}}$ become longer. For $\mathrm{P}_{2} \mathrm{~W}_{17}-2 \mathrm{C}_{12} / \mathrm{C}_{12} \mathrm{EO}_{6}$ mixtures at $8 \mathrm{mM}$ (Figure $2 \mathrm{~A}$ ), there is no significant increase in the peak intensity or shift observed in the scattering 
patterns, nonetheless the trend is still weakly observed from the values extracted from the fits. However, this increased repulsion between micelles becomes much more pronounced in the $\mathrm{P}_{2} \mathrm{~W}_{17}-2 \mathrm{C}_{18} / \mathrm{C}_{12} \mathrm{EO}_{6}$ mixtures (Figure 2D).

As seen from Table 3, the volume fraction values, $\varphi$, obtained for the 1:3 solutions are lower than those found for the 3:1 solutions, but $N_{\text {agg }}$ increases (except for the $\mathrm{P}_{2} \mathrm{~W}_{17-2} \mathrm{C}_{14} / \mathrm{C}_{12} \mathrm{EO}_{6}$ mixtures which have a very small variation in $N_{\text {agg }}$ among 3 ratios). The volume fraction differences are supported by the fact that the singletailed nonionic surfactant has a smaller molecular volume compared to that of $\mathrm{P}_{2} \mathrm{~W}_{17}-2 \mathrm{C}_{\mathrm{n}}$. It is also seen that the ellipticity $(\varepsilon)$ of the micelles increases with the $\mathrm{C}_{12} \mathrm{EO}_{6}$ content in these mixtures at a given concentration. The fitted shell thickness ( $t$ ) varies between 12 and $17 \AA$ which are comparable to the dry $\mathrm{P}_{2} \mathrm{~W}_{17}$ headgroup size which lies in the range of $12-18 \AA .^{38}$

When the total concentration of surfactant in solution was increased to $16 \mathrm{mM}$ without changing the mole fractions, the micelles elongate slightly compared to those formed at $8 \mathrm{mM}$ (see the micellar ellipticities listed in Table 3).

Table 3. Fitted model parameters for $\mathrm{P}_{2} \mathrm{~W}_{17}-2 \mathrm{C}_{\mathrm{n}} / \mathrm{C}_{12} \mathrm{EO}_{6}$ mixed micelles at concentrations of $8 \mathrm{mM}$ and $16 \mathrm{mM}$.

\begin{tabular}{|c|c|c|c|c|c|c|c|c|}
\hline $\begin{array}{c}\mathrm{P}_{2} \mathrm{~W}_{17}-2 \mathrm{C}_{\mathrm{n}}: \\
\mathrm{C}_{12} \mathrm{EO}_{6}\end{array}$ & $\begin{array}{l}N_{\text {agg }} \\
( \pm 3)\end{array}$ & $\begin{array}{c}Z_{m}(e) \\
( \pm 1)\end{array}$ & $\begin{array}{c}Z_{p}(e) \\
( \pm 25 \%)^{b}\end{array}$ & $\begin{array}{c}R_{\min } \\
(\AA)( \pm 1)\end{array}$ & $\begin{array}{c}\varepsilon \\
( \pm 0.3)\end{array}$ & $\begin{array}{c}\varphi \\
( \pm 0.002)\end{array}$ & $\begin{array}{c}\mathrm{A}\left(\AA^{2}\right) \\
( \pm 5)\end{array}$ & $\begin{array}{l}\mathrm{t}(\AA) \\
( \pm 1)\end{array}$ \\
\hline \multicolumn{9}{|c|}{$8 \mathrm{mM} \mathrm{P}_{2} \mathrm{~W}_{17}-2 \mathrm{C}_{12} / \mathrm{C}_{12} \mathrm{EO}_{6}$ mixtures } \\
\hline $3: 1$ & 94 & 4 & 0.07 & 16 & 2.9 & 0.011 & 80 & 15 \\
\hline $1: 1$ & 125 & 6 & 0.23 & 15 & 3.6 & 0.007 & 64 & 13 \\
\hline $1: 3$ & 148 & 9 & 1.93 & 15 & 3.8 & 0.008 & 54 & 14 \\
\hline \multicolumn{9}{|c|}{$16 \mathrm{mM} \mathrm{P}_{2} \mathrm{~W}_{17}-2 \mathrm{C}_{12} / \mathrm{C}_{12} \mathrm{EO}_{6}$ mixtures } \\
\hline $3: 1$ & 88 & 4 & 0.13 & 16 & 3.0 & 0.035 & 86 & 16 \\
\hline $1: 1$ & 92 & 4 & 0.21 & 14 & 3.3 & 0.026 & 73 & 14 \\
\hline $1: 3$ & 139 & 9 & 1.09 & 17 & 4.5 & 0.020 & 59 & 15 \\
\hline \multicolumn{9}{|c|}{$8 \mathrm{mM} \mathrm{P}_{2} \mathrm{~W}_{17}-2 \mathrm{C}_{14} / \mathrm{C}_{12} \mathrm{EO}_{6}$ mixtures } \\
\hline $3: 1$ & 49 & 5 & 0.14 & 16 & 1.7 & 0.016 & 109 & 16 \\
\hline $1: 1$ & 74 & 9 & 0.23 & 18 & 1.9 & 0.010 & 84 & 13 \\
\hline $1: 3$ & 69 & 11 & 1.15 & 15 & 2.1 & 0.007 & 74 & 13 \\
\hline \multicolumn{9}{|c|}{$16 \mathrm{mM} \mathrm{P}_{2} \mathrm{~W}_{17}-2 \mathrm{C}_{14} / \mathrm{C}_{12} \mathrm{EO}_{6}$ mixtures } \\
\hline $3: 1$ & 28 & 8 & 0.40 & 14 & 2.1 & 0.021 & 128 & 12 \\
\hline $1: 1$ & 64 & 9 & 0.34 & 17 & 1.9 & 0.014 & 86 & 11 \\
\hline $1: 3$ & 61 & 11 & 2.02 & 14 & 2.9 & 0.012 & 77 & 13 \\
\hline \multicolumn{9}{|c|}{$8 \mathrm{mM} \mathrm{P}_{2} \mathrm{~W}_{17}-2 \mathrm{C}_{16} / \mathrm{C}_{12} \mathrm{EO}_{6}$ mixtures } \\
\hline $3: 1$ & 51 & 5 & 0.13 & 21 & 1 & 0.011 & 112 & 14 \\
\hline $1: 1$ & 51 & 6 & 0.26 & 17 & 1.7 & 0.008 & 101 & 13 \\
\hline
\end{tabular}




\begin{tabular}{|c|c|c|c|c|c|c|c|c|}
\hline $1: 3$ & 110 & 8 & 0.37 & 17 & 2.7 & 0.007 & 70 & 14 \\
\hline \multicolumn{9}{|c|}{$D_{6}$ mixtures } \\
\hline $3: 1$ & 61 & 5 & 0.14 & 21 & 1 & 0.035 & 113 & 17 \\
\hline $1: 1$ & 63 & 5 & 0.19 & 16 & 2.2 & 0.017 & 104 & 13 \\
\hline $1: 3$ & 108 & 4 & 0.11 & 16 & 3.4 & 0.022 & 69 & 16 \\
\hline \multicolumn{9}{|c|}{$8 \mathrm{mM} \mathrm{P}_{2} \mathrm{~W}_{17}-2 \mathrm{C}_{18} / \mathrm{C}_{12} \mathrm{EO}_{6}$ mixtures } \\
\hline $3: 1$ & 55 & 8 & -- & 21 & 1 & 0.011 & -- & 14 \\
\hline $1: 1$ & 72 & 9 & -- & 22 & 1 & 0.0096 & -- & 14 \\
\hline $1: 3$ & 129 & 12 & -- & 18 & 3.1 & 0.0074 & -- & 13 \\
\hline \multicolumn{9}{|c|}{$16 \mathrm{mM} \mathrm{P}{ }_{2} \mathrm{~W}_{17}-2 \mathrm{C}_{18} / \mathrm{C}_{12} \mathrm{EO}_{6}$ mixtures } \\
\hline $3: 1$ & 72 & 8 & -- & 23 & 1 & 0.025 & -- & 13 \\
\hline $1: 1$ & 94 & 9 & -- & 24 & 1 & 0.017 & -- & 12 \\
\hline $1: 3$ & 132 & 11 & -- & 18 & 3.3 & 0.014 & & \\
\hline
\end{tabular}

${ }^{a} R_{\min }$, the minimum radius of core; $R_{\max }$, the maximum radius of core; $\varepsilon, R_{\max } / R_{\min }$ (ellipticity); $\varphi$, volume fraction; SLD, Neutron scattering length density; t, Shell thickness; $\mathrm{N}_{\mathrm{agg}}$, aggregation number; $Z_{m}$, charge per micelle; $Z_{p}$, charge per $P_{2} W_{17}-2 C_{n}$ molecule; $A$, averaged area per molecule.

${ }^{\mathrm{b}}$ for this parameter the error is estimated at $25 \%$ of the value.

A phase diagram concerning the shapes of the micelles compared to their compositions was obtained from the SANS modelling results and is given in Figure 4. $\mathrm{C}_{12} \mathrm{EO}_{6}$ is known to form rod-like micelles in water, measured using three different techniques reported in the literature. ${ }^{39}$ Once mixed with $\mathrm{P}_{2} \mathrm{~W}_{17}-2 \mathrm{C}_{\mathrm{n}}$, the micelle shape depends on the mixing ratio and the hydrophobic tail length of $\mathrm{P}_{2} \mathrm{~W}_{17}-2 \mathrm{C}_{n}$. For compositions rich in $\mathrm{P}_{2} \mathrm{~W}_{17}-2 \mathrm{C}_{18}$ or $\mathrm{P}_{2} \mathrm{~W}_{17}-2 \mathrm{C}_{16}$, more globular micelles were formed. For nonionic-surfactant rich compositions, more elongated ellipsoidal micelles were favoured.

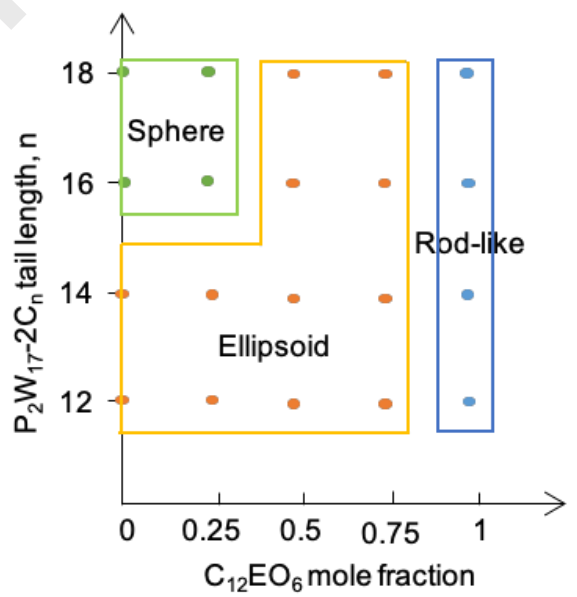

Figure 4. Phase diagram of binary $\mathrm{P}_{2} \mathrm{~W}_{17}-2 \mathrm{C}_{\mathrm{n}} / \mathrm{C}_{12} \mathrm{EO}_{6}$ mixtures at 8 and $16 \mathrm{mM}, \mathrm{n}$, the carbon atom number in the hydrophobic $P_{2} W_{17}-2 C_{n}$ tails is given on the $y$-axis and the $x$-axis corresponds to the $\mathrm{C}_{12} \mathrm{EO}_{6}$ mole fraction. 
Micellar composition. The interaction parameters, $\beta$, calculated from the experimental $\mathrm{CMC}$ values, indicate antagonism in mixed micelle formation. In the analysis of SANS data from the $h-P_{2} W_{17}-2 C_{n} / h-C_{12} E_{6} O_{6}$ systems, the composition of the micelles cannot be calculated from the shell SLD obtained by the fitting of the SANS patterns, due to the complexity of shell composition discussed before.

To evaluate the mixing mole fractions of the two surfactants in the micelles and the deviations from ideal mixing, the fully hydrogenated $\mathrm{C}_{12} \mathrm{EO}_{6}$ was replaced by taildeuterated $\mathrm{C}_{12} \mathrm{EO}_{6}\left(\mathrm{~d}-\mathrm{C}_{12} \mathrm{EO}_{6}\right)$ in the mixtures without changing the mole fractions or total surfactant molar concentrations. Through the fitted core SLD in the partially deuterated mixtures, the micellar compositions in these systems were calculated. The SANS data and their fits are given in SI Figure 9 and 10. Results from the SANS-derived $\mathrm{C}_{12} \mathrm{EO}_{6}$ mole fractions in $\mathrm{P}_{2} \mathrm{~W}_{17}-2 \mathrm{C}_{n} / \mathrm{C}_{12} \mathrm{EO}_{6}(\mathrm{n}=12$ and 14$)$ systems obtained at both concentrations with three mixing ratios are shown in Figure 5 (markers) and are compared to the theoretical curves for ideal (solid line) and nonideal (dashed line) mixing. The micellar compositions at non-ideal mixing conditions were calculated using $\bar{\beta}$ listed in combined with the isotopic substitution method to determine the micellar composition in order to compare with the values of Table 2.

Table 2 according to the pseudo-phase-separation model based on regular solution theory. ${ }^{37,40}$ The relationship between the micellar composition and the total surfactant concentration was proposed by Bauduin ${ }^{37}$ and is given as:

$$
\mathrm{y}_{1}=\frac{-(\mathrm{C}-\Delta)+\left((\mathrm{C}-\Delta)^{2}+4 \mathrm{C} x_{1} \Delta\right)^{1 / 2}}{2 \Delta}
$$

where $\Delta=f_{2} C M C_{2}-f_{1} C M C_{1}$ in the case of non-ideal mixing. $\mathrm{y}_{1}$ is the mole fraction of surfactant 1 in the micelle, $f_{1}$ and $f_{2}$ are activity coefficients which are expressed as discussed above. $\mathrm{C}$ is the overall concentration of the surfactants. 

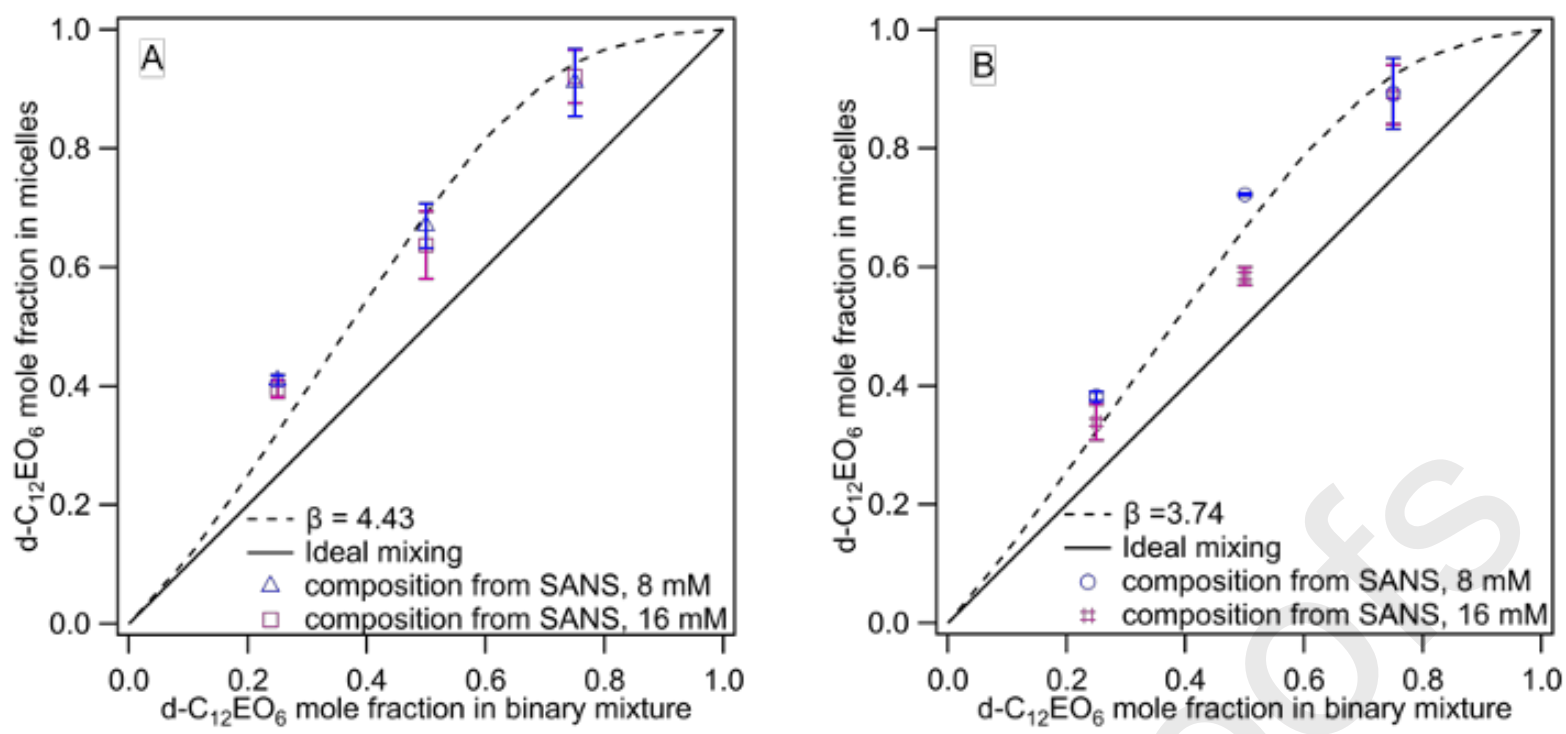

Figure 5. $\mathrm{d}-\mathrm{C}_{12} \mathrm{EO}_{6}$ micellar mole fraction extracted from SANS fitting (markers), ideal mixing (solid line) and non-ideal mixing (dashed line) for the (A) $\mathrm{P}_{2} \mathrm{~W}_{17}-2 \mathrm{C}_{12} / \mathrm{C}_{12} \mathrm{EO}_{6}$ system and (B) $\mathrm{P}_{2} \mathrm{~W}_{17^{-}}$ $2 \mathrm{C}_{14} / \mathrm{C}_{12} \mathrm{EO}_{6}$ system at a total surfactant molar concentration of $8 \mathrm{mM}$ and $16 \mathrm{mM}$.

As seen in Figure 5, at these mixing ratios studied for the two systems, positive deviations from ideal mixing are observed in SANS fitted results (markers), as expected from the positive $\beta$ values. They are much closer to agreement with the results obtained from the non-ideal mixing with the given interaction parameters. The nonionic-rich mixtures represent the smallest departure from the non-ideal mixing. When the two surfactants have equivalent mole fractions, the SANS fitted micellar compositions show the largest deviation from the non-ideal mixing conditions in both systems. The standard deviations of the micellar compositions are small but increase when the nonionic surfactant ratio increases.

The differences between the micellar composition from SANS fitting and non-ideal mixing theory can be explained by taking into account of the errors in the SANS fitting on one side, and the uncertainties in the measurements of the CMC values used to extract $\bar{\beta}$ on the other. Moreover, as illustrated in Figure 5 , the composition of the micelles is found to differ with the overall surfactant concentration, becoming closer to ideal at higher concentration as expected. 
$\mathrm{P}_{2} \mathrm{~W}_{17}-2 \mathrm{C}_{16} / \mathrm{d}-\mathrm{C}_{12} \mathrm{EO}_{6}$ and $\mathrm{P}_{2} \mathrm{~W}_{17}-2 \mathrm{C}_{18} / \mathrm{d}-\mathrm{C}_{12} \mathrm{EO}_{6}$ systems were not measured using SANS. However, the results discussed above have shown that the interaction parameter can be used to predict the micellar composition. Therefore, the averaged interaction parameter $(\bar{\beta}=3.02)$ for the $\mathrm{P}_{2} \mathrm{~W}_{17}-2 \mathrm{C}_{16} / \mathrm{C}_{12} \mathrm{EO}_{6}$ system was used to predict the micellar compositions for the $\mathrm{P}_{2} \mathrm{~W}_{17}-2 \mathrm{C}_{16} / \mathrm{C}_{12} \mathrm{EO}_{6}$ mixtures (see Table 4). It could not be calculated for $\mathrm{P}_{2} \mathrm{~W}_{17}-2 \mathrm{C}_{18} / \mathrm{C}_{12} \mathrm{EO}_{6}$ systems using interaction parameters as the CMCs could not be measured. The obtained mole fractions considering the unfavourable interactions are called corrected mole fractions in the following discussion and are labelled as $[M]_{\text {cor }}$ (where $M$ represents $P_{2} W_{17}-2 C_{n}$ or $\left.\mathrm{C}_{12} \mathrm{EO}_{6}\right)$.

Table 4. $\left[\mathrm{C}_{12} \mathrm{EO}_{6}\right]_{\text {cor }}$ of $\mathrm{P}_{2} \mathrm{~W}_{17}-2 \mathrm{C}_{16}: \mathrm{C}_{12} \mathrm{EO}_{6}$ mixtures at $8 \mathrm{mM}$ and $16 \mathrm{mM}$ with three different $\mathrm{C}_{12} \mathrm{EO}_{6}$ mixing mole fractions.

\begin{tabular}{ccc}
\hline $\mathrm{C}_{12} \mathrm{EO}_{6}$ mole fraction & \multicolumn{2}{c}{$\left[\mathrm{C}_{12} \mathrm{EO}_{6}\right]_{\text {cor }}$} \\
\cline { 2 - 3 } & \multicolumn{1}{c}{$8 \mathrm{mM}$} & $16 \mathrm{mM}$ \\
\hline 0.250 & $0.265 \pm 0.050$ & $0.257 \pm 0.048$ \\
0.500 & $0.550 \pm 0.098$ & $0.525 \pm 0.098$ \\
0.750 & $0.804 \pm 0.132$ & $0.779 \pm 0.115$ \\
\hline
\end{tabular}

Aggregation number, surface charge and area per molecule. The aggregation numbers, $\mathrm{N}_{\text {agg, }}$, were calculated from the volume of the core divided by the corresponding tail volume per surfactant $\left(\mathrm{V}_{\text {tail }}\right)$. $\mathrm{V}_{\text {tail }}$ can be calculated using the equation:

$$
\mathrm{V}_{\text {tail }}=\mathrm{V}_{2 \mathrm{Cn}} \times\left[\mathrm{P}_{2} \mathrm{~W}_{17}-2 \mathrm{C}_{n}\right]_{\mathrm{cor}}+\mathrm{V}_{\mathrm{C} 12} \times\left[\mathrm{C}_{12} \mathrm{EO}_{6}\right]_{\mathrm{cor}}
$$

where $\left[\mathrm{P}_{2} \mathrm{~W}_{17}-2 \mathrm{C}_{n}\right]_{\text {cor }}$ and $\left[\mathrm{C}_{12} \mathrm{EO}_{6}\right]_{\text {cor }}$ are corrected mole fractions of $\mathrm{P}_{2} \mathrm{~W}_{17}-2 \mathrm{C}_{\mathrm{n}}$ and $\mathrm{C}_{12} \mathrm{EO}_{6}$ in the micelles respectively (calculated in the Micellar Composition section below), $\mathrm{V}_{2 \mathrm{Cn}}$ and $\mathrm{V}_{\mathrm{C} 12}$ are the estimated tail volume of each surfactant, therefore are the volume of the double- $\mathrm{C}_{n} \mathrm{H}_{2 n+1}$ tails and $\mathrm{C}_{12} \mathrm{H}_{25}$ tail estimated via Tanford equation. ${ }^{41}$ Consequently, the charge number of each $P_{2} W_{17}-2 C_{n}$ molecule, $Z_{p}$, was 
calculated according to the obtained aggregation numbers and corrected $\mathrm{P}_{2} \mathrm{~W}_{17}-2 \mathrm{C}_{\mathrm{n}}$ mole fractions. Values of $Z_{p}$ (refer to Table 3) increase with nonionic species present in the mixtures.

The micellar surface charge $\left(Z_{m}\right)$ of our systems are found to be smaller than those found in SDS/ $\mathrm{C}_{12} \mathrm{EO}_{6}$ systems (which range between 8 and $21 \mathrm{e}$ ) ${ }^{42}$ even if the POM headgroups could be potentially highly charged (monovalent SDS versus hexavalent POM headgroups). The RMSA structure factor used for fitting, utilises the pair potential between two spherical colloids within a linearization approximation taking the Debye-Hückel form. This method, however, becomes inadequate to describe highly charged objects for which the electrostatic energy of a micro-ion near the colloid surface largely exceeds $\mathrm{k}_{\mathrm{B}} \mathrm{T}$ (thermal energy). ${ }^{43}$ The obtained "surface charge" $Z_{m}$, in that case, is the charge at a surface far from the actual surface of the micelles, therefore the bare surface charge is replaced by an effective or re-normalised quantity. ${ }^{43}$ This explains the relatively low surface charge in our systems given by SANS modelling.

However, the re-normalised charges obtained still can be compared for discussion. With a given mixture containing $\mathrm{P}_{2} \mathrm{~W}_{17}-2 \mathrm{C}_{12}$ or $\mathrm{P}_{2} \mathrm{~W}_{17-2}-\mathrm{C}_{14}$, the charge per $\mathrm{P}_{2} \mathrm{~W}_{17^{-}}$ $2 \mathrm{C}_{\mathrm{n}}$ surfactant molecule $\left(\mathrm{Z}_{\mathrm{p}}\right)$ becomes larger when more $\mathrm{C}_{12} \mathrm{EO}_{6}$ molecules are present in the mixtures, suggesting the $\mathrm{P}_{2} \mathrm{~W}_{17}-2 \mathrm{C}_{\mathrm{n}}$ molecules become more ionised as they are diluted by the $\mathrm{C}_{12} \mathrm{EO}_{6}$ molecules within the micelles. This is consistent with the discussion above on the degree of ionisation values obtained from conductivity measurements. For the longer-tailed counterpart, $\mathrm{P}_{2} \mathrm{~W}_{17}-\mathrm{C}_{16}$, the trend is not as obvious. Comparing the absolute ionisation values among different $\mathrm{P}_{2} \mathrm{~W}_{17}-2 \mathrm{C}_{n}$ surfactants in the given mixtures, longer-tailed $\mathrm{P}_{2} \mathrm{~W}_{17}-2 \mathrm{C}_{n}$ are less ionised. This is similar to what has been observed for the singular $\mathrm{P}_{2} \mathrm{~W}_{17}-2 \mathrm{C}_{\mathrm{n}}$ surfactant systems, ${ }^{19}$ 
and also for single tail quaternary ammonium surfactants. ${ }^{44}$ and sodium alkyl sulfates. $^{45}$

The average area per molecule $(A)$ values are listed in Table 3, estimated using the surface area of the mixed micelle divided by its corresponding aggregation number. The dry $\mathrm{P}_{2} \mathrm{~W}_{17}$ headgroup has a cross-sectional area $\left(\mathrm{A}_{\mathrm{P} 2 \mathrm{~W} 17}\right)$ around $120 \AA^{2}$, and the cross-sectional area for $\mathrm{EO}_{6}$ group $\left(\mathrm{A}_{\mathrm{EO}}\right)$ lies in the range of 46 to $58 \AA^{2} .46$ Estimated area per molecule values $\left(\mathrm{A}_{\mathrm{cor}}\right)$ are listed in SI Table 3, calculated using the corrected mole fraction of each component:

$$
A_{c o r}=A_{P 2 W 17} \times\left[P_{2} W_{17}-2 C_{n}\right]_{c o r}+A_{E O 6} \times\left[C_{12} E_{6}\right]_{c o r}
$$

$A$ and $A_{\text {cor }}$ give similar results if the uncertainties are included. It is also seen these values decrease with the $\mathrm{C}_{12} \mathrm{EO}_{6}$ component, giving larger packing parameters, ${ }^{47,48}$ which contributes to the formation of more elongated micelles. This is also reflected by the increasing ellipticity values obtained from SANS fitting.

\section{Discussion}

The experimental CMC values of binary mixtures are found to be higher than those calculated for ideal mixing which implies that non-ideal mixing is present for these systems. They are found to decrease rapidly with an increase in the nonionic surfactant concentration in the mixtures because the $C M C$ of the $P_{2} W_{17}-2 C_{n}$ component is much higher than that of the $\mathrm{C}_{12} \mathrm{EO}_{6}{ }^{19}{ }^{132}$ Positive $\beta$ values were obtained, indicating an unfavourable interaction between the two types of surfactant molecules. These interactions are different from those reported for other anionic/nonionic binary surfactant systems where normally attractive interactions between surfactants were found. ${ }^{34,37,49-52}$

For anionic/nonionic binary surfactant systems, in general it has been suggested that the insertion of nonionic surfactant molecules between the ionic surfactant molecules 
reduces the electrostatic repulsion between the ionic headgroups allowing the formation of micelles at a lower concentration. ${ }^{52}$ Furthermore, for mixtures of an anionic surfactant with $\mathrm{C}_{m} \mathrm{EO}_{n}$ nonionic surfactant $(\mathrm{m}$ : the number of methylene groups, n: the number of ethylene oxide groups), the negatively charged headgroups interact with the slightly positively charged ether oxygen atoms, ${ }^{49-51}$ i.e. oxonium ions, present in the polyoxyethylene groups at several points on the micelle surface. For example, a synergistic effect between surfactant molecules have been reported for sodium bis(2-ethyl hexyl) sulfosuccinate $/ \mathrm{C}_{12} \mathrm{EO}_{4}$ and $\mathrm{SDS} / \mathrm{C}_{10} \mathrm{EO}_{5}$ mixtures. ${ }^{34,}{ }^{37}$ In both systems, the experimental CMC values are lower than those expected in the case of ideal mixing. $\mathrm{NaDS} / \mathrm{C}_{12} \mathrm{EO}_{12}$ and $\mathrm{Mg}(\mathrm{DS})_{2} / \mathrm{C}_{12} \mathrm{EO}_{12}$ have also been reported to have attractive interaction between surfactant molecules. ${ }^{52}$ The $M g(D S)_{2}$ turned out to have weaker interactions with nonionic surfactants in comparison to NaDS due to strong condensation of the $\mathrm{Mg}^{2+}$ counterions onto the micelles.

The favourable mixing of nonionic surfactants with either anionic ${ }^{34,35,52}$ or cationic ${ }^{53}$, ${ }^{54}$ surfactants has been frequently reported. Such synergism is mainly attributed to the screening of electrostatic repulsions between the ionic components introduced by the ethoxylated chains of the nonionic surfactant coil. Reports of an unfavourable mixing between ionic surfactants and nonionic surfactants in mixtures are uncommon. ${ }^{55}$ We have not found any previous reports of an unfavorable interaction between anionic surfactants and nonionic surfactants in mixtures. An antagonism between alkylediyl- $\alpha$ - $\omega$-bis(alkyldimethylammonium) dibromide, a dichain cationic surfactant, with different tail lengths and a nonionic surfactant, polyoxyethylene(23) lauryl ether (Brij35) has been reported by Akbaş. ${ }^{55}$ In that case, the antagonism was attributed to a greater amount of Brij35 in the mixed state since they obtain a higher $\beta$ value when the mole fraction of Brij35 was increased. Compared to the reported 
favourable mixing, ${ }^{34,35,52}$ found for mixed systems containing ionic surfactants and nonionic surfactants with a lower repetition number of EO in the hydrophilic headgroup, crowding of the large hydrophilic headgroup of the Brij35 on the micelle surface may contribute to the unfavourable mixing. Our mixed $P O M-2 C_{n} / C_{12} E_{6}$ systems were found to exhibit similar antagonistic behaviour, which increases with increased amounts of the nonionic species, even though the nonionic surfactant $\left(\mathrm{C}_{12} \mathrm{EO}_{6}\right)$ used has a smaller headgroup than Brij35. The largest antagonistic interactions were obtained between $\mathrm{P}_{2} \mathrm{~W}_{17}-2 \mathrm{C}_{12}$ and $\mathrm{C}_{12} \mathrm{EO}_{6}$ (averaged $\beta$ value: $\bar{\beta}=$ $4.4 \pm 0.8)$. The interaction becomes less prominent when the $P_{2} W_{17}-2 C_{n}$ component bears a longer hydrocarbon chain length. The smallest $\bar{\beta}, 3.0 \pm 0.6$, was found in $\mathrm{P}_{2} \mathrm{~W}_{17}-2 \mathrm{C}_{16} / \mathrm{C}_{12} \mathrm{EO}_{6}$ mixtures, giving the smallest absolute deviations between the measured $\mathrm{CMC}$ values and those predicted for ideal mixing, compared to $\mathrm{P}_{2} \mathrm{~W}_{17^{-}}$ $2 \mathrm{C}_{\mathrm{n}} / \mathrm{C}_{12} \mathrm{EO}_{6}$ ( $\mathrm{n}=12$ or 14 ) systems. A similar phenomenon of the effect of tail length on the interaction was also reported for the $\mathrm{C}_{12} \mathrm{EO}_{23}$ and alkanediyl- $\alpha$ - $\omega$-bis (alkyldimethyl ammonium) dibromide system discussed above. The antagonistic interaction parameters of that system decreased from 3.584 to 0.087 when the number of carbons in the chain of the cationic surfactant increased from 12 to $16 .^{56}$ The principal interactions in the surfactant mixing are: ${ }^{57}(1)$ electrostatic interactions between headgroups, (2) ion-dipole attractions between ionic and nonionic headgroups, (3) steric interactions between bulky groups, (4) van der Waals interactions between hydrophobic groups, and (5) hydrogen bonding among constituent surfactant molecules.

In an anionic-nonionic surfactant mixed system, the micelles are stabilized primarily through the contact of hydrocarbon chains of both surfactants, termed hydrophobic interactions. It is apparent that when our $\mathrm{P}_{2} \mathrm{~W}_{17}-2 \mathrm{C}_{\mathrm{n}}$ is present with the nonionic 
surfactant, the unfavourable interactions between the two kinds of molecules are strong, therefore giving a positive $\beta$ value, despite the hydrophobic interactions which drive the formation of mixed micelles. Several effects may induce unfavourable interactions: first and foremost, bare POMs are known to self-assemble in solutions driven by counterion-mediated electrostatic interaction. ${ }^{58,} 59$ The tendency of the $\mathrm{P}_{2} \mathrm{~W}_{17}$ headgroups to assemble possibly hinders the aggregation of the two kinds of surfactant molecules to some extent. Secondly, POMs and their $\mathrm{K}^{+}$ counter-ions are both considered to compete with the hydration of the polyethylene oxide head in the $\mathrm{C}_{12} \mathrm{EO}_{6}$. POMs are considered as "super-chaotropes" due to their large size and delocalized charge. ${ }^{60,61}$ They therefore disrupt the adjacent water molecules that bond to the polyethylene oxide headgroup through hydrogen bonds. $\mathrm{K}^{+}$ions (introduced by $\mathrm{P}_{2} \mathrm{~W}_{17}-2 \mathrm{C}_{n}$ ), are termed as "structure makers", which means that water molecules surrounding them are more organized compared to pure water. $^{62}$ These could result in a lower hydration of the $\mathrm{EO}_{6}$ groups located between $\mathrm{P}_{2} \mathrm{~W}_{17}-2 \mathrm{C}_{\mathrm{n}}$ molecules. The reduced hydration in $\mathrm{EO}_{6}$ group may contribute to the antagonistic mixing behaviour of the two components in the micelles. Moreover, unfavourable mixing behaviour is could also be caused by the structures of the two hydrophilic headgroups. Ethylene oxide chains usually behave as Gaussian coils ${ }^{46,49 \text {, }}$ 63 and maintain a characteristic size unperturbed in a saturated adsorption layer instead of forming extended chains into the solutions. The energetically favourable coil configuration is smaller ( $10.29 \AA$, calculated from the equation in reference ${ }^{46,64}$ ) than the $\mathrm{P}_{2} \mathrm{~W}_{17}$ headgroup (around $12 \AA$ ). ${ }^{38}$ In these mixed micelles, the $\mathrm{EO}_{6}$ groups may be forced to take on a configuration away from their most energetically favourable conformation, which may also contribute to the observed antagonistic effect. 


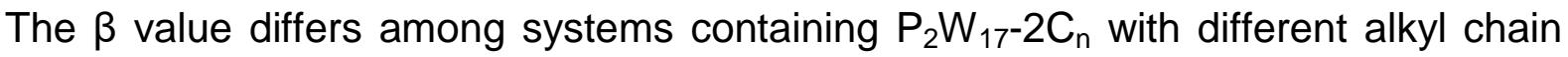
lengths. The variations can be attributed to the effects of alkyl chain symmetry and asymmetry, which has been studied for cationic and anionic surfactant mixed systems. $^{65}$ In the case of a system with high alkyl chain symmetry $\left(\mathrm{P}_{2} \mathrm{~W}_{17^{-}}\right.$ $2 \mathrm{C}_{12} / \mathrm{C}_{12} \mathrm{EO}_{6}$ ), packing of the surfactants tails is favoured and therefore, strong unfavourable interactions between headgroups occurs. For two surfactants with different alkyl tail lengths, a dense packing is sterically unfavourable. Therefore, $\beta$ decreases with increasing difference between tail lengths. This is corroborated by the larger $A_{c o r}$ values found for $P_{2} W_{17}-2 C_{14} / C_{12} E_{6}$ and $P_{2} W_{17}-2 C_{16} / C_{12} E O_{6}$ systems compared to those of the mixtures containing $\mathrm{P}_{2} \mathrm{~W}_{17}-2 \mathrm{C}_{12}$.

The phase behaviour of the individual di-alkyl chain surfactants, $P_{2} W_{17}-2 C_{n}$ have been previously reported by $\mathrm{us}^{19}$ and that of the nonionic surfactant, $\mathrm{C}_{12} \mathrm{EO}_{6}$, is well established. ${ }^{39} \mathrm{P}_{2} \mathrm{~W}_{17}-2 \mathrm{C}_{\mathrm{n}}$ surfactants have a relatively large headgroup (ca. $12 \AA$ in length with an area per molecule around $\left.120 \AA^{2}\right),{ }^{38}$ which favours the formation of globular or ellipsoidal micelles in water, depending on the tail length. The addition of the nonionic surfactant $\mathrm{C}_{12} \mathrm{EO}_{6}$, which tends to form rod-like micelles in water, into the $\mathrm{P}_{2} \mathrm{~W}_{17}-2 \mathrm{C}_{\mathrm{n}}$ system therefore induces the elongation of the mixed micelles. On addition of $\mathrm{C}_{12} \mathrm{EO}_{6}$ to the solution of $\mathrm{P}_{2} \mathrm{~W}_{17}-2 \mathrm{C}_{12}$, the nonionic surfactant molecules incorporate into the ionic surfactant micelles, leading to a modest increase of the elliptical ratio from 2.9 to 3.8. However, the micelles also grow considerably in size, and aggregation number and the resulting increase in total micelle charge leads to an obvious shift in the micelle interaction peak in the scattering pattern as the nonionic content increases.

The phase behaviour and the microstructure of ionic and nonionic molecules mixtures have been studied in the literature. ${ }^{34,42}$ Most of them also report the growth 
of micelles upon addition of nonionic surfactant to charged surfactant molecules in solutions. A similar shift of the micelle interaction peak has also been reported for $\mathrm{SDS} / \mathrm{C}_{12} \mathrm{EO}_{6}$ and $\mathrm{SDS} / \mathrm{C}_{12} \mathrm{EO}_{8}$ mixtures which have been studied by Penfold et al. ${ }^{42}$ For $\mathrm{SDS} / \mathrm{C}_{12} \mathrm{EO}_{6}$ mixtures, the elliptical ratio increased from 1.3 to 2.4 when the $\mathrm{C}_{12} \mathrm{EO}_{6}$ mole percent increased from $20 \%$ to $90 \%$. Sodium bis(2-ethyl hexyl)sulfosuccinate (AOT), an anionic surfactant which is double-tailed, similar to $\mathrm{P}_{2} \mathrm{~W}_{17}-2 \mathrm{C}_{\mathrm{n}}$ surfactants, was also mixed with $\mathrm{C}_{12} \mathrm{EO}_{6}$ but shows favourable aggregation. ${ }^{34}$ Similarly, more elongated micelles were formed in the nonionic rich mixtures in this system. The differences in interaction type between the $A O T / \mathrm{C}_{12} \mathrm{EO}_{6}$ system and our systems cannot be explained in terms of molecular geometry since both anionic surfactants are double-tailed as monomers (although the branched tails in AOT are much shorter than the linear chains in the $\left.\mathrm{P}_{2} \mathrm{~W}_{17}-2 \mathrm{C}_{n}\right)$. Consequently, the counterion-mediated electrostatic interactions and counterion condensation onto the micelles must play a crucial role in the aggregation of molecules into micelles at equilibrium in our systems.

As reported in Table 3, there is an increase in the micellar surface charge with the increase of the nonionic surfactant mole fraction. This appears to occur because the $\mathrm{P}_{2} \mathrm{~W}_{17}-2 \mathrm{C}_{\mathrm{n}}$ molecules ionise more when more nonionic surfactant molecules are inserted into the micelles. This is also suggested by the calculated $Z_{p}$ values. The modest increase in surface charge observed for our system is the opposite to the results that have been found in $\mathrm{SDS} / \mathrm{C}_{12} \mathrm{EO}_{8}, \mathrm{SDS} / \mathrm{C}_{12} \mathrm{EO}_{6}{ }^{42}$ and sodium bis(2-ethyl hexyl) sulfosuccinate/ $\mathrm{C}_{12} \mathrm{EO}_{4}$ mixtures, ${ }^{34}$ which give a decrease in surface charge with the increase of nonionic surfactant content. This may be due to the fact that the $\mathrm{P}_{2} \mathrm{~W}_{17}$ headgroups bear more ionisable counterions which can respond when $\mathrm{C}_{12} \mathrm{EO}_{6}$ is mixed into the micelles, than SDS which has only one counterion per 
molecule. Additional interactions, arising from counterion-mediated electrostatic interactions, which do not usually exist in other systems, may also affect the overall micellar charges.

In summary, this study reported an antagonistic binary surfactant system $\mathrm{P}_{2} \mathrm{~W}_{17^{-}}$ $2 \mathrm{C}_{\mathrm{n}} / \mathrm{C}_{12} \mathrm{EO}_{6}$. This antagonism, as discussed above, may be attributed to a few different interactions: counterion-mediated interactions between $\mathrm{P}_{2} \mathrm{~W}_{17}$ units, the large size and delocalized charge of $\mathrm{P}_{2} \mathrm{~W}_{17}$, and the unfolding of the ethylene oxide headgroups, but is moderated by packing caused by hydrophobic interactions between surfactant tails. The interactions become less favourable when the two components have the same hydrophobic tail length. The increasing mole fraction of the nonionic component induces the formation of more elongated micelles. Increased shielding of the $\mathrm{P}_{2} \mathrm{~W}_{17}$ headgroups by the nonionic surfactant also increases the degree of $\mathrm{P}_{2} \mathrm{~W}_{17}$ ionisation in the mixed micelles.

\section{Conclusion}

Previous studies report a synergistic interactions between ionic and nonionic polyethylene oxide surfactants, which arises due to electrostatic attractions between headgroups in the mixed surfactants, in addition to hydrophobic interaction between tails. ${ }^{34,35,52}$ In contrast, this study reports an antagonistic effect in mixtures of $\mathrm{P}_{2} \mathrm{~W}_{17^{-}}$ headed surfactants and $\mathrm{C}_{12} \mathrm{EO}_{6}$. Data from SANS, tensiometry and conductometry were used to study and quantify the unfavourable interactions between the two surfactant species and determine the micellar compositions of the mixtures. An unfavourable interaction was previously observed for Brij35/alkylediyl-a-wbis(alkyldimethylammonium) dibromide, which similarly increased with increasing amount of Brij35 and decreased as the tail length of the ionic species increased. ${ }^{55}$ This was ascribed to crowding of the large polyethylene oxide headgroups of the 
Brij35 at the micelle surface. In our system, although part of the antagonistic effect may be attributed to the unfolding of the ethylene oxide headgroups in the mixed micelles, other contributions to unfavourable mixing include the counterion-mediated attractive interactions between $\mathrm{P}_{2} \mathrm{~W}_{17}$ units and the large size and delocalized charge of $\mathrm{P}_{2} \mathrm{~W}_{17}$. However, formation of mixed micelles still occurs due to the hydrophobic interactions between surfactant tails. This study could provide a fundamental reference for the study of unfavourable mixing systems, especially those containing surfactants that have highly-charged headgroups, a large size difference between the mixed surfactant components and nonionic components where the optimal headgroup conformation is detrimentally affected by the presence of the other species. Despite the unfavourable mixing, these mixed micelles, are stable and hence can be envisaged for use in several applications. For example, taking into account the remarkable photocatalytic properties of polyoxometalates, ${ }^{66}$ the tuneable micellar composition, through changing the mixing molar ratio, can be used to form supramolecular catalysts with tailored properties. Another example would be their use as templating agents for the synthesis of functionalised mesoporous materials with customised polyoxometalate loadings and spacing within the pores as designer photocatalysts.

\section{Acknowledgements}

Funding: A. Di. thanks University of Bath and China Scholarship Council for supporting her PhD studies. The authors would like to thank the ISIS Neutron and Muon Spallation Source for the award of beam time on beamline LARMOR and LOQ (experiment nos. 1810278 and 1720185) that contributed to the results presented here. The raw SANS data can be found at DOI: 10.5286/ISIS.E.RB1810278 and 10.5286/ISIS.E.RB1720185, while the CMC data and reduced SANS data supporting 
this paper can be found in the University of Bath Research Data Archive, 2019 DOI: 10.15125/BATH-00XXX.

This work benefited from the use of the SasView application, originally developed under NSF Award DMR-0520547. SasView also contains code developed with funding from the EU Horizon 2020 programme under the SINE2020 project Grant 654000.

Supplementary Information: Neutron scattering lengths for surfactant alkyl tails, graphs of surface tension and conductivity data used to calculated CMC values, tabulated CMC values for the binary mixtures studied, comparison of measured CMCs to that expected for demixing, further SANS data and fits, table of calculated area per molecule for mixed micelles.

\section{References}

1. Stupp, S. I.; LeBonheur, V.; Walker, K.; Li, L. S.; Huggins, K. E.; Keser, M.; Amstutz, A., Supramolecular Materials: Self-Organized Nanostructures. Science 1997, 276 (5311), 384.

2. Dwars, T.; Paetzold, E.; Oehme, G., Reactions in Micellar Systems. Angew. Chem. Int. Ed. 2005, 44 (44), 7174-7199.

3. Qin, L.; Zhang, L.; Jin, Q.; Zhang, J.; Han, B.; Liu, M., Supramolecular Assemblies of Amphiphilic L-Proline Regulated by Compressed CO2 as a Recyclable Organocatalyst for the Asymmetric Aldol Reaction. Angew. Chem. Int. Ed. 2013, 52 (30), 7761-7765.

4. Lehmann, J.; Gaita-Arino, A.; Coronado, E.; Loss, D., Spin Qubits with Electrically Gated Polyoxometalate Molecules. Nat. Nanotechnol. 2007, 2 (5), 312.

5. Yue, B.; Zhou, Y.; Xu, J.; Wu, Z.; Zhang, X.; Zou, Y.; Jin, S., Photocatalytic Degradation of Aqueous 4-chlorophenol by Silica-Immobilized Polyoxometalates. Environ. Sci. Technol. 2002, 36, 1325-1329. 
6. Sadakane, M.; Steckhan, E., Electrochemical Properties of Polyoxometalates As Electrocatalysts. Chem. Rev. 1998, 98, 219-238.

7. López, X.; Bo, C.; Poblet, J. M., Electronic Properties of Polyoxometalates: Electron and Proton Affinity of Mixed-Addenda Keggin and Wells- Dawson Anions. J. Am. Chem. Soc. 2002, 124, 12574-12582.

8. Yamase, T.; Pope, M. T., Polyoxometalate Chemistry for Nano-Composite Design. Springer US: Boston, MA, 2002.

9. Li, H.; Pang, S.; Wu, S.; Feng, X.; Müllen, K.; Bubeck, C., Layer-By-Layer Assembly and UV Photoreduction of Graphene-Polyoxometalate Composite Films for Electronics. J. Am. Chem. Soc. 2011, 133, 9423-9429.

10. Kim, Y.; Shanmugam, S., Polyoxometalate-Reduced Graphene Oxide Hybrid Catalyst: Synthesis, Structure, and Electrochemical Properties. ACS Appl. Mater. Interfaces 2013, 5, 12197-12204.

11. Qi, W.; Wu, L., Polyoxometalate/Polymer Hybrid Materials: Fabrication and Properties. Polym. Int. 2009, 58 (11), 1217-1225.

12. Salles, R.; Abécassis, B.; Derat, E.; Brouri, D.; Bernard, A.; Zhang, Q.; Proust, A.; Desmarets, C.; Izzet, G., Hierarchical Self-Assembly of Polyoxometalate-Based Organo Palladium(II) Metallomacrocycles via Electrostatic Interactions. Inorganic Chemistry 2020, 59 (4), 2458-2463.

13. Zhang, J.; Song, Y.-F.; Cronin, L.; Liu, T., Self-Assembly of Organic-Inorganic Hybrid Amphiphilic Surfactants with Large Polyoxometalates as Polar Head Groups. J. Am. Chem. Soc. 2008, 130 (44), 14408-14409. 
14. Yin, P.; Wang, J.; Xiao, Z.; Wu, P.; Wei, Y.; Liu, T., Polyoxometalate-Organic Hybrid Molecules as Amphiphilic Emulsion Catalysts for Deep Desulfurization. Chemistry - A European Journal 2012, 18 (30), 9174-9178.

15. Zhang, J.; Song, Y.-F.; Cronin, L.; Liu, T., Self-Assembly of Organic-Inorganic Hybrid Amphiphilic Surfactants with Large Polyoxometalates as Polar Head Groups. Journal of the American Chemical Society 2008, 130 (44), 14408-14409.

16. Yu, S.-J.; Han, Y.-K.; Wang, W., Unravelling concentration-regulated self-assembly of a protonated polyoxometalate-polystyrene hybrid. Polymer 2019, 162, 73-79.

17. Han, Y.; Xiao, Y.; Zhang, Z.; Liu, B.; Zheng, P.; He, S.; Wang, W., Synthesis of Polyoxometalate-Polymer Hybrid Polymers and Their Hybrid Vesicular Assembly. Macromolecules 2009, 42 (17), 6543-6548.

18. Jallet, V.; Guillemot, G.; Lai, J.; Bauduin, P.; Nardello-Rataj, V.; Proust, A., Covalent amphiphilic polyoxometalates for the design of biphasic microemulsion systems. Chemical Communications 2014, 50 (50), 6610-6612.

19. Di, A.; Schimitt, J.; da Silva, M.; Errington, J.; Edler, K., Self-Assembly of Amphiphilic Polyoxometalates for the Preparation of Hybrid Mesoporous Polyoxometalate-Titania Catalysts. 2019, submitted.

20. Rubingh, D.; Mittal, K., Solution Chemistry of Surfactants. Plenum: New York, 1979; Vol. 1, p 337-354.

21. Heenan, R.; King, S. Development of Small-Angle Diffractometer LOQ at the ISIS Pulsed Neutron Source; Joint Institute for Nuclear Research: Dubna, 1st-4th September 1992, 1993.

22. Bennington, S. M., Instruments on the ISIS Second Target Station. Nucl. Instrum. Methods Phys. Res., Sect. A 2009, 600 (1), 32-34. 
23. Arnold, O.; Bilheux, J.-C.; Borreguero, J.; Buts, A.; Campbell, S. I.; Chapon, L.;

Doucet, M.; Draper, N.; Leal, R. F.; Gigg, M., Mantid-Data Analysis and Visualization Package for Neutron Scattering and $\mu$ SR Experiments. Nucl. Instrum. Methods Phys. Res., Sect. A 2014, 764, 156-166.

24. Wignall, G. T.; Bates, F., Absolute Calibration of Small-Angle Neutron Scattering Data. J. Appl. Crystallogr. 1987, 20, 28-40.

25. Guiner, A.; Fournet, G.; Walker, C.; Yudowitch, K., Small-Angle Scattering of X-rays. John Wiley and Sons: New York, 1955.

26. Kotlarchyk, M.; Chen, S. H., Analysis of Small Angle Neutron Scattering Spectra From Polydisperse Interacting Colloids. J. Chem. Phys. 1983, 79, 2461-2469.

27. Berr, S., Solvent Isotope Effects on Alkytrimethylammonium Bromide Micelles as a Function of Alkyl Chain Length. J. Phys. Chem. 1987, 91, 4760-4765.

28. Hansen, J.-P.; Hayter, J. B., A Rescaled MSA Structure Factor for Dilute Charged Colloidal Dispersions. Mol. Phys. 1982, 46 (3), 651-656.

29. Pilsl, H.; Hoffmann, H.; Hofmann, S.; Kalus, J.; Kencono, A.; Lindner, P.; Ulbricht, W., Shape Investigation of Mixed Micelles By Small Angle Neutron Scattering. J. Phys. Chem. $1993,97,2745-2754$.

30. Griffiths, P.; Whatton, M.; Abbott, R.; Kwan, W.; Pitt, A.; Howe, A.; King, S.; Heenan, R., Small-Angle Neutron Scattering and Fluorescence Studies of Mixed Surfactants with Dodecyl Tails. J. Colloid Interface Sci. 1999, 215, 114-123.

31. Srinivasan, K.; Kay, R. L., Pressure Dependence of The Dielectric Constant of H2O and D2O. J. Chem. Phys. 1974, 60, 3645-3648. 
32. McDermott, D.; Lu, J.; Lee, E.; Thomas, R.; Rennie, A., Study of the Adsorption from Aqueous Solution of Hexaethylene Glycol Monododecyl Ether on Silica Substrates Using the Technique of Neutron Reflection. Langmuir 1992, 8, 1204-1210.

33. Domínguez, A.; Fernández, A.; González, N.; Iglesias, E.; Montenegro, L., Determination of Critical Micelle Concentration of Some Surfactants By Three Techniques. J. Chem. Educ. 1997, 74, 1227.

34. Grillo, I.; Penfold, J., Self-Assembly of Mixed Anionic and Nonionic Surfactants in Aqueous Solution. Langmuir 2011, 27, 7453-7463.

35. Bakshi, M. S.; Singh, J.; Singh, K.; Kaur, G., Mixed Micelles of Cationic Gemini with Tetraalkyl Ammonium and Phosphonium Surfactants: the Head Group and Hydrophobic Tail Contributions. Colloids Surf., A 2004, 234, 77-84.

36. Holland, P. M.; Rubingh, D. N., Cationic Surfactants: Physical Chemistry. Marcel Dekker: New York, 1991.

37. Misselyn-Bauduin, A.-M.; Thibaut, A.; Grandjean, J.; Broze, G.; Jérôme, R., Mixed Micelles of Anionic-Nonionic and Anionic-Zwitterionic Surfactants Analyzed By Pulsed Field Gradient NMR. Langmuir 2000, 16, 4430-4435.

38. Mitchell, S. G.; Jesús, M., The Synergistic Behavior of Polyoxometalates and Metal Nanoparticles: From Synthetic Approaches to Functional Nanohybrid Materials. J. Mater. Chem. 2012, 22, 18091-18100.

39. Gapinski, J.; Szymanski, J.; Wilk, A.; Kohlbrecher, J.; Patkowski, A.; Hołyst, R., Size and Shape of Micelles Studied by Means of SANS, PCS, and FCS. Langmuir 2010, 26, 93049314.

40. Clint, J. H., Micellization of Mixed Nonionic Surface Active Agents. J. Chem. Soc. Faraday Trans. I 1975, 71, 1327-1334. 
41. Tanford, C., Theory of Micelle Formation in Aqueous Solutions. J. Phys. Chem. 1974, 78, 2469-2479.

42. Penfold, J.; Tucker, I.; Thomas, R.; Staples, E.; Schuermann, R., Structure of Mixed Anionic/Nonionic Surfactant Micelles: Experimental Observations Relating to the Role of Headgroup Electrostatic and Steric Effects and the Effects of Added Electrolyte. J. Phys. Chem. B 2005, 109, 10760-10770.

43. Bocquet, L.; Trizac, E.; Aubouy, M., Effective Charge Saturation in Colloidal Suspensions. J. Chem. Phys. 2002, 117, 8138-8152.

44. Buckingham, S. A.; Garvey, C. J.; Warr, G. G., Effect of Head-Group Size on Micellization and Phase Behavior in Quaternary Ammonium Surfactant Systems. J. Phys. Chem. 1993, 97, 10236-10244.

45. Lebedeva, N. V.; Shahine, A.; Bales, B. L., Aggregation Number-Based Degrees of Counterion Dissociation in Sodium N-Alkyl Sulfate Micelles. J. Phys. Chem. B 2005, 109, 19806-19816.

46. Sedev, R., Limiting Area Per Molecule of Nonionic Surfactants At the Water/Air Interface. Langmuir 2001, 17 (2), 562-564.

47. Israelachvili, J. N.; Mitchell, D. J.; Ninham, B. W., Theory of Self-Assembly of Hydrocarbon Amphiphiles into Micelles and Bilayers. J. Chem. Soc. Faraday Trans. I/ 1976, $72,1525-1568$.

48. Nagarajan, R., Molecular Packing Parameter and Surfactant Self-Assembly: the Neglected Role of the Surfactant Tail. Langmuir 2002, 18, 31-38.

49. Schick, M., Surface Films of Nonionic Detergents-I. Surface Tension Study. J. Colloid Sci. 1962, 17, 801-813. 
50. Hsiao, L.; Dunning, H.; Lorenz, P., Critical Micelle Concentrations of Polyoxyethylated Nonionic Detergents. J. Phys. Chem. 1956, 60, 657-660.

51. Becher, P., Nonionic Surface-Active Compounds. V. Effect of Electrolyte. J. Colloid Sci. $1962,17,325-333$.

52. Joshi, T.; Mata, J.; Bahadur, P., Micellization and Interaction of Anionic and Nonionic Mixed Surfactant Systems in Water. Colloids Surf., A 2005, 260, 209-215.

53. Joshi, T.; Bharatiya, B.; Kuperkar, K., Micellization and interaction properties of aqueous solutions of mixed cationic and nonionic surfactants. J. Disp. Sci. Technol. 2008, 29 (3), 351-357.

54. Javadian, S.; Gharibi, H.; Bromand, Z.; Sohrabi, B., Electrolyte effect on mixed micelle and interfacial properties of binary mixtures of cationic and nonionic surfactants. J. Colloid Interface Sci. 2008, 318 (2), 449-456.

55. Akbaş, H.; Kasapoğlu, S.; Boz, M., Aggregation behavior and intermolecular interaction of binary surfactant mixtures based on cationic Geminis and nonionic surfactants. Colloid and Polymer Science 2015, 293 (12), 3429-3437.

56. Akbaş, H.; Boz, M.; Dinç, A., Interactions between Cationic Gemini Surfactants and Nonionic Surfactant in Aqueous Solutions. In International Conference on Chemical, Environment \& Biological Sciences, Kuala Lumpur (Malaysia), 2014.

57. Sheikh, M. S.; Dar, A. A., Interaction of A Cationic Gemini Surfactant With Conventional Surfactants in the Mixed Micelle and Monolayer Formation in Aqueous Medium. J. Colloid Interface Sci. 2009, 333, 605-612.

58. Yin, P.; Li, D.; Liu, T., Solution Behaviors and Self-Assembly of Polyoxometalates As Models of Macroions and Amphiphilic Polyoxometalate-Organic Hybrids As Novel Surfactants. Chem. Soc. Rev. 2012, 41, 7368-7383. 
59. Luo, J.; Liu, T., Competition and Cooperation among Different Attractive Forces in Solutions of Inorganic-Organic Hybrids Containing Macroionic Clusters. Langmuir 2019, 35, 7603-7616.

60. Buchecker, T.; Schmid, P.; Renaudineau, S.; Diat, O.; Proust, A.; Pfitzner, A.; Bauduin, P., Polyoxometalates in the Hofmeister Series. Chem. Commun. 2018, 54, 18331836.

61. Naskar, B.; Diat, O.; Nardello-Rataj, V. r.; Bauduin, P., Nanometer-Size Polyoxometalate Anions Adsorb Strongly on Neutral Soft Surfaces. J. Phys. Chem. C 2015, 119, 20985-20992.

62. Holtzscherer, C.; Candau, F., Salt Effect on Solutions of Nonionic Surfactants and Its Influence on the Stability of Polymerized Microemulsions. J. Colloid Interface Sci. 1988, 125, 97-110.

63. Nishikido, N., Mixed Micelles of Polyoxyethylene-Type Nonionic and Anionic Surfactants in Aqueous Solutions. J. Colloid Interface Sci. 1977, 60, 242-251.

64. Nikas, Y.; Puvvada, S.; Blankschtein, D., Surface Tensions of Aqueous Nonionic Surfactant Mixtures. Langmuir 1992, 8 (11), 2680-2689.

65. Regev, O.; Khan, A., Alkyl Chain Symmetry Effects in Mixed Cationic-Anionic Surfactant Systems. J. Colloid Interface Sci. 1996, 182, 95-109.

66. Costa-Coquelard, C.; Schaming, D.; Lampre, I.; Ruhlmann, L., Photocatalytic reduction of $\mathrm{Ag} 2 \mathrm{SO} 4$ by the Dawson anion $\alpha-[\mathrm{P} 2 \mathrm{~W} 18062] 6-$ and tetracobalt sandwich complexes. Appl. Catal. B-Environ 2008, 84 (3-4), 835-842.

\section{CRediT authorship contribution statement}


Andi Di: Conceptualization, Methodology, Investigation, Formal analysis, WritingOriginal draft, Writing - Review \& Editing, Visualization, Funding acquisition. Julien Schmitt: Investigation, Validation, Writing - Review \& Editing. Kun Ma: Resources, Investigation. Marcelo A. Da Silva: Investigation, Writing - Review \& Editing. Naomi S. Elstone: Writing - Review \& Editing. Najet Mahmoudi: Investigation, Resources. Peixun Li: Resources. Adam Washington: Investigation, Resources. Zi Wang: Investigation, Resources. R. John Errington: Conceptualization, Writing -Review \& Editing. Karen J Edler: Conceptualization, Supervision, Resources, Writing -Review \& Editing, Funding acquisition, Project Administration.

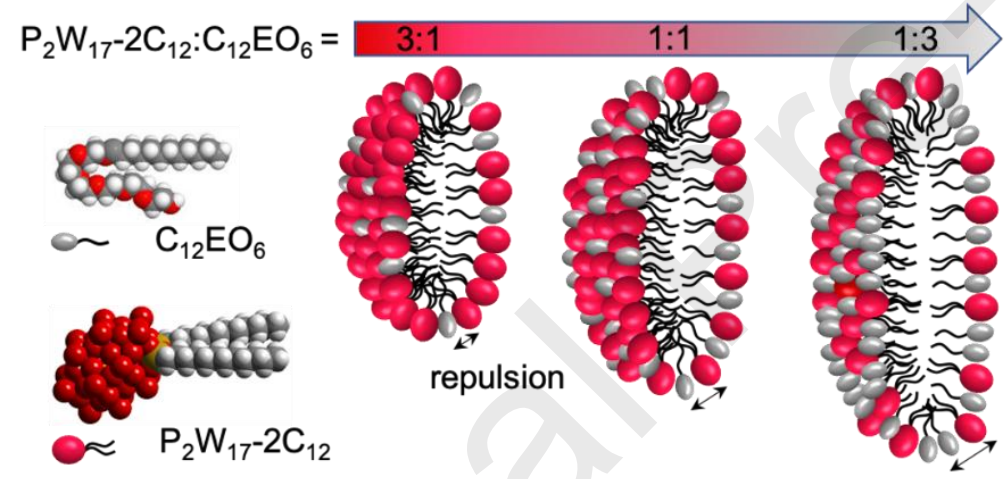

